Graphical Abstract

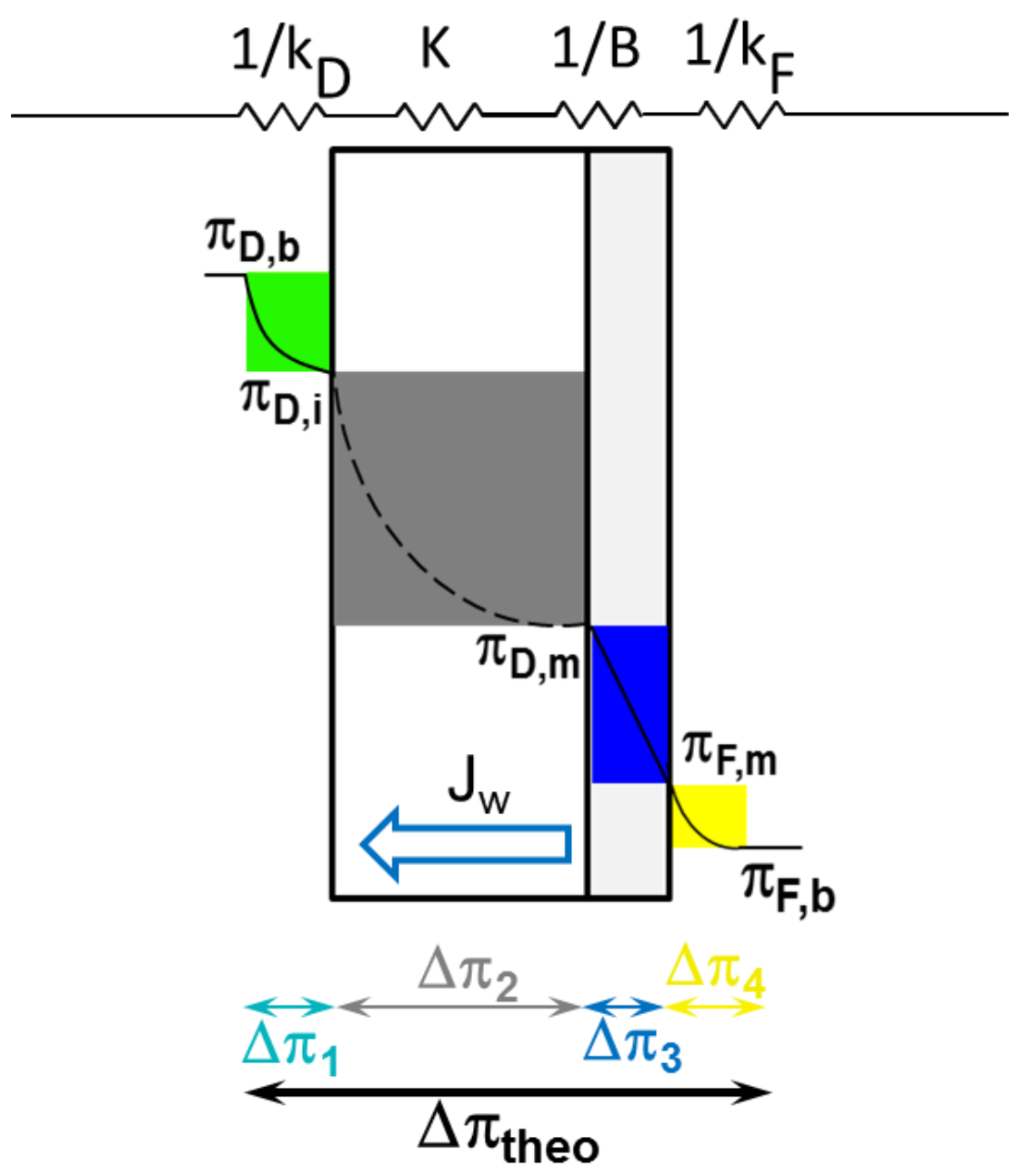




\title{
Proper Accounting of Mass Transfer Resistances in Forward Osmosis: Improving the Accuracy of Model Predictions of Structural Parameter
}

\author{
Nhu-Ngoc Bui ${ }^{1,2}$, Jason T. Arena ${ }^{1}$, Jeffrey R. McCutcheon ${ }^{1, *}$ \\ ${ }^{1}$ Department of Chemical \& Biomolecular Engineering \\ Center for Environmental Sciences and Engineering; University of Connecticut; Storrs, \\ Connecticut, USA \\ ${ }^{2}$ Physical and Life Sciences Directorate, Lawrence Livermore National Laboratory, Livermore, \\ California, USA
}

Submitted to

Journal of Membrane Science

Keywords: Structural parameter, concentration polarization, reflection coefficient, membrane resistance, pressure retarded osmosis

*Corresponding author

Email: jeff@engr.uconn.edu

Phone: 860-486-4601 


\begin{abstract}
This work demonstrates a more accurate method for calculating structural parameter (S) of asymmetric osmotic membranes using experimental data and a theoretical flux model which encapsulates all significant boundary layer phenomena. External boundary layer effects on the porous side of the membrane have been neglected in many current models. In these models, external concentration polarization (ECP) effects get combined with the internal concentration polarization (ICP), resulting in inflated S values. In this study, we proposed a new flux model in which ECP effects are accounted for so that $S$ can be more accurately measured. This model considered the in-series resistances for solute transport based on intrinsic properties of the membrane as well as boundary layers at membrane surfaces and within the support layer. The results indicate that ICP is less severe than previously predicted and that cross-flow velocity, temperature and concentration of the draw and the feed solutions impact both external and internal concentration polarization. Our calculations also surprisingly show that changes in cross-flow velocity impact internal concentration polarization due to induced mixing within the support layer. Also, we suggest that it is critical to consider the "residence time" of solutes in the vicinity of the selective layer in determining the membrane selectivity.
\end{abstract}




\section{Introduction}

Forward Osmosis (FO) and pressure retarded osmosis (PRO) have recently been revitalized as a sustainable and versatile membrane-based separation technology platform for water and power production, respectively. These processes are driven by the osmotic pressure difference between two solutions separated by a semi-permeable membrane. There are a number of configurations, uses and system integration methods proposed in the literature [1-3]. Some of these processes include treating impaired water and landfill leachate [4-7], recovery of high-value dissolved solids in food processing and pharmaceutical industries [8, 9], desalination $[1,10-12]$, or salinity-gradient power generation [3, 13-21]. FO has been widely studied in recent years, mainly focusing on development of improved membrane structures [22-32] and draw solutes [33-37] for efficient operation.

To design membranes for various FO processes, it is important to understand critical structure-performance relationships, especially with respect to mass transfer. This has led to a number of theoretical transport models to predict osmotic water flux coupled with reverse salt flux across FO membranes [21, 23, 38-50]. Many of these models have been used to predict the severity of concentration polarization (CP), a mass transfer phenomenon that reduces osmotic driving force. Specifically, internal concentration polarization (ICP), which mimics a stagnant diffusion limited boundary layer occurring within an asymmetric membrane support structure, has largely been recognized as the major impediment to membrane flux performance [38-40, 51]. Lee et. al. derived one of the first mathematical models describing transport during osmosis across asymmetric membranes and was among the first to describe ICP [39]. Still emphasizing the importance of ICP, McCutcheon and coworkers [38] developed a flux model in which the impact of external concentration polarization at the selective layer surface $\left(E C P^{s}\right)$ was combined. Phillip and coworker presented a model describing the reverse solute permeation across an asymmetric membrane in FO [43]. Recently, Yip et.al. [21] and Tiraferri et.al. [52] 
developed models in which ICP, ECPs and reverse salt permeation were all taken into account to predict flux performance in FO. In these models, although the osmotic flux behaviors appeared to be predicted accurately, the effect of ECP occurring on the porous side of the membrane structure $\left(E C P^{p}\right)$ has commonly been ignored. This assumption was valid for early membranes that exhibited low flux or having large structural parameters relative to the external boundary layer thickness. However, with the advent of high performance membranes operated at higher flux or at low crossflow velocities, ECP ${ }^{P}$ becomes more substantial and the assumption is no longer valid $[50,62]$.

Neglecting the ECP will result in an inaccurate accounting of the severity of ICP. If neglected, existing models simply lump ECP ${ }^{\mathrm{p}}$ into the ICP term. This results in an overprediction of structural parameter since the ECP effects are misallocated to structural resistances in the support side of the membrane. Limited attention on $\mathrm{ECP}^{\mathrm{p}}$ could misrepresent the severity of ICP and misdirect research priorities to support layer development when in fact $\mathrm{ECP}^{\mathrm{p}}$ could become a more critical problem as better membranes become available.

A recent computational fluid dynamics simulation on forward osmosis systems using asymmetric membranes supported this hypothesis in revealing the non-negligible ECP even when high cross-flow velocity and slip velocity at the porous surface were accounted [50]. If we are to continue using experimental data to characterize structural parameter, a comprehensive mass transfer model is needed to account for this $\mathrm{ECP}^{\mathrm{p}}$ so that proper attention is paid to both membrane design and external fluid dynamics conditions. Improved understanding of this phenomenon is essential for better overall system modeling as pilot- and full-scale systems are built and cost models established.

This study demonstrates an updated theoretical model to predict osmotic flux performance of asymmetric and thin-film composite membranes in FO. ECP ${ }^{p}$ was incorporated 
in such a flux model to advance understanding of its impacts to osmotic flux. The related mass transfer resistances, e.g. ICP, ECP ${ }^{\mathrm{p}}, \mathrm{ECP}^{\mathrm{s}}$, solute resistivity and structural parameter, were effectively de-convoluted from one another. This led to a new governing equation defining solute resistivity and structural parameter. Furthermore, new definitions of membrane reflection coefficient and total resistance to solute transport emerge from this work. "Residence time" of solutes at membrane surfaces is, for the first time, discussed as it relates to membrane selectivity. This model is supported by experimental data from two commercial forward osmosis membranes.

\section{Theory and Model Development}

Figure 1 shows a schematic of the solute concentration gradient across a thin-film composite membrane operating in FO mode (porous support layer faces a high-salinity draw solution) [62]. The effective driving force for osmosis exists only at the interfaces of the selective layer. From the bulk draw solution, solutes must diffuse through the porous support to the interface between the support and selective layers. Once there, a small amount of solute diffuses across the selective layer to the lower-saline feed [43]. Below, a new model is derived which accounts for ICP, ECP ${ }^{s}$ and $E C P^{p}$ coupled with the reverse solute flux.

Figure 1

\subsection{Updated Model: Incorporating ECP on Both Sides of the Membrane}

\subsubsection{For the FO Mode}

Osmotic water flux across the selective layer, $\mathrm{J}_{\mathrm{w}}$, is defined as:

$$
J_{w}=A\left(\sigma \Delta \pi_{b}-\Delta P\right)=A\left(\Delta \pi_{m}-\Delta P\right)=A\left[\left(\pi_{D, m}-\pi_{F, m}\right)-\Delta P\right]
$$

where, $A$ is the intrinsic water permeability coefficient, or permeance, of the membrane, $\sigma$ is the reflection coefficient of the membrane, $\Delta \pi_{m}$ is the effective osmotic pressure difference across 
the selective layer, $\Delta \mathrm{P}$ is the transmembrane hydrostatic pressure. $\Delta \mathrm{P}$ is typically zero or close to zero in many FO applications.

Reverse salt flux, $\mathrm{J}_{\mathrm{s}}{ }^{\mathrm{a}}$, across the selective layer:

$$
J_{s}^{a}=B \Delta C_{m}=B\left(C_{D, m}-C_{F, m}\right)
$$

where, $B$ is the intrinsic solute permeability coefficient of the membrane, $C_{D, m}$ and $C_{F, m}$ are the solute concentrations at the selective interface in the draw and feed, respectively.

As water permeates (i.e. osmotic water flux, $J_{w}$ ) from the feed to the draw, it dilutes the draw solution within the porous support and draw solution boundary layer causing both dilutive ICP and ECP. At the same time, solutes diffuse from the bulk draw, through the porous support, to the interface of this support and the selective layer due to a concentration gradient from dilution of the draw solution. This transport is described by the commonly used convectiondiffusion equation, consisting of a diffusive term caused by the solute concentration gradient and a negative convective term caused by the mass flow of water across the membrane in the opposite direction [39].

$$
J_{s}^{d}=D \frac{d C(x)}{d x}-J_{w} C(x)
$$

where, $D$ is the solute diffusion coefficient. $D$ is then referred to $D_{S}$ or $D_{D}$ when accounting for solute diffusivity inside the support layer or in the draw solution, respectively. In the porous support structure, $D_{s}$ is the bulk diffusion coefficient corrected with the porosity, $\varepsilon$, and tortuosity, $\tau$, of the support, or $D_{s}=\frac{D_{D} \varepsilon}{\tau}$.

At steady state, the solute fluxes across the selective layer and the porous support are equal:

$$
J_{s}{ }^{a}=J_{s}{ }^{d}
$$




$$
\text { or } \quad B\left(C_{D, m}-C_{F, m}\right)=D \frac{d C(x)}{d x}-J_{w} C(x)
$$

To solve the differential equation, we consider the following boundary conditions:

Boundary conditions: $\left\{\begin{array}{l}x=0, C(x)=C_{D, i} \\ x=-t_{s}, C(x)=C_{D, m}, D=D_{s}=\frac{D_{D} \varepsilon}{\tau} \\ x=\delta_{D}, C(x)=C_{D, b}, D=D_{D}\end{array}\right\}$

We also define $\frac{t_{s}}{D_{s}}=\frac{S\left(\frac{\varepsilon}{\tau}\right)}{D_{D}\left(\frac{\varepsilon}{\tau}\right)}=\frac{S}{D_{D}}$ and $\frac{\delta_{D}}{D_{D}}=\frac{1}{k_{D}}$ where, $S=t_{s} \tau / \varepsilon$ is the structural parameter of the membrane support, $\delta_{D}$ and $k_{D}$ are the thickness of the boundary layer and the mass transfer coefficient in the draw side, respectively.

Solving eqn. (5) for the boundary conditions, the draw solution concentration is defined by:

$$
C_{D, m}=C_{D, b} \exp \left[-J w\left(\frac{1}{k_{D}}+\frac{S}{D_{D}}\right)\right]+\frac{B \Delta C_{m}}{J_{w}}\left\{\exp \left[-J w\left(\frac{1}{k_{D}}+\frac{S}{D_{D}}\right)\right]-1\right\}
$$

In this equation, the draw solute concentration at the support - selective layer interface, $\mathrm{C}_{\mathrm{D}, \mathrm{m}}$, is the sum of two components on the right expression. The first component is the concentration of the bulk draw solution, $\mathrm{C}_{\mathrm{D}, \mathrm{b}}$, accounted for dilutive $E C P^{\mathrm{p}}$ and ICP effects which are described by the exponential terms of $\left(-\frac{J_{w}}{k_{D}}\right)$ and $\left(-\frac{J_{W} S}{D_{D}}\right)$. The second contribution to the increase of the solute concentration at the membrane surface is from the reverse solute permeation.

On the feed side, the convective water flux from the feed to the draw carries solutes from the bulk feed to the selective layer where they theoretically are rejected and accumulate. This is a concentrative external concentration polarization, with a boundary layer thickness of $\delta_{F}=D_{F} k_{F}$, where $D_{F}$ is solute diffusion coefficient and $k_{F}$ is the mass transfer coefficient in the feed. The salt flux within this $\mathrm{CECP}^{\mathrm{s}}$ layer is, also, a combination of the diffusive and convective terms: 


$$
J_{s}^{f}=D \frac{d C(z)}{d z}-J_{w} C(z)
$$

At steady state, $J_{s}{ }^{a}=J_{s}^{f}$

Or

$$
B\left(C_{D, m}-C_{F, m}\right)=D \frac{d C(z)}{d z}-J_{w} C(z)
$$

With boundary conditions: $\left\{\begin{array}{l}z=0, C(z)=C_{F, m} \\ z=-\delta_{F}, C(z)=C_{F, b}\end{array}\right\}$

Integrating (8) with respect to the boundary conditions above, yields

$$
C_{F, m}=C_{F, b} \exp \left(\frac{J_{w}}{k_{F}}\right)+\frac{B \Delta C_{m}}{J_{w}}\left[\exp \left(\frac{J_{w}}{k_{F}}\right)-1\right]
$$

Subtracting eqn. (9) to (7), $\Delta C_{m}$ can be derived as:

$$
\begin{gathered}
\Delta C_{m}=\left(C_{D, m}-C_{F, m}\right)=C_{D, b} \exp \left[-J w\left(\frac{1}{k_{D}}+\frac{S}{D_{D}}\right)\right]-C_{F, b} \exp \left(\frac{J_{w}}{k_{F}}\right)+\frac{B \Delta C_{m}}{J_{w}}\left\{\exp \left[-J w\left(\frac{1}{k_{D}}+\frac{S}{D_{D}}\right)\right]-\exp \left(\frac{J_{w}}{k_{F}}\right)\right\}(10) \\
\text { or } \quad \Delta C_{m}=\frac{C_{D, b} \exp \left[-J w\left(\frac{1}{k_{D}}+\frac{S}{D_{D}}\right)\right]-C_{F, b} \exp \left(\frac{J_{w}}{k_{F}}\right)}{1+\frac{B}{J_{w}}\left\{\exp \left(\frac{J_{w}}{k_{F}}\right)-\exp \left[-J w\left(\frac{1}{k_{D}}+\frac{S}{D_{D}}\right)\right]\right\}}
\end{gathered}
$$

Assuming van't Hoff theory is valid in this concentration zone where osmotic pressure is linearly proportional to the salt concentration, the final equation for calculating osmotic water flux in the FO mode becomes:

$$
J_{w}{ }^{F O}=A\left\{\frac{\pi_{D, b} \exp \left[-J w\left(\frac{1}{k_{D}}+\frac{S}{D_{D}}\right)\right]-\pi_{F, b} \exp \left(\frac{J_{w}}{k_{F}}\right)}{1+\frac{B}{J_{w}}\left\{\exp \left(\frac{J_{w}}{k_{F}}\right)-\exp \left[-J w\left(\frac{1}{k_{D}}+\frac{S}{D_{D}}\right)\right]\right\}}\right\}
$$




\subsubsection{For the PRO Mode}

Likewise, following a similar derivation the complete water flux equation for the PRO mode, including the non-zero hydraulic pressure gradient across the selective layer, can be achieved as follows,

$$
\left.J_{w}^{P R O}=A\left\{\frac{\pi_{D, b} \exp \left(-\frac{J_{w}}{k_{D}}\right)-\pi_{F, b} \exp \left[J_{w}\left(\frac{1}{k_{F}}+\frac{S}{D_{F}}\right)\right]}{1+\frac{B}{J_{w}}\left\{\exp \left[J_{w}\left(\frac{1}{k_{F}}+\frac{S}{D_{F}}\right)-\exp \left(-\frac{J_{w}}{k_{D}}\right)\right]\right\}}-\Delta P\right\}\right]
$$

Where $\Delta P$ is the hydraulic pressure applied on the draw side to retard the osmotic water flux from the feed, in conjunction with a hydroturbine providing the means to extract mechanical work from osmosis [39]. The complete derivation is provided in the supplementary material available online.

\subsection{New derivation of solute resistivity in FO and PRO}

From eqn. (12) and (13), the solute resistivity, $K_{D}$ and $K_{F}$ in FO and PRO, respectively, can be derived as:

In FO,

$$
K_{D}=\frac{S}{D_{D}}=-\frac{1}{k_{D}}-\frac{1}{J_{w}} \ln \left[\frac{\frac{J_{w}}{A}+\left(\frac{B}{A}+\pi_{F, b}\right) \exp \left(\frac{J_{w}}{k_{F}}\right)}{\left(\frac{B}{A}+\pi_{D, b}\right)}\right]
$$

In PRO,

$$
K_{F}=\frac{S}{D_{F}}=-\frac{1}{k_{F}}+\frac{1}{J_{w}} \ln \left[\frac{\left(\frac{B}{A}+\pi_{D, b}\right) \exp \left(-\frac{J_{w}}{k_{D}}\right)-\frac{J_{w}}{A}-\Delta P\left[1+\frac{B}{J_{w}}\left\{\exp \left[J_{w}\left(\frac{1}{k_{F}}+K_{F}\right)\right]-\exp \left(-\frac{J_{w}}{k_{D}}\right)\right\}\right]}{\left(\frac{B}{A}+\pi_{F, b}\right)}\right]
$$

In non-pressurized PRO mode, with $\Delta P=0$ : 


$$
K_{F}=\frac{S}{D_{F}}=-\frac{1}{k_{F}}+\frac{1}{J_{w}} \ln \left[\frac{\left(\frac{B}{A}+\pi_{D, b}\right) \exp \left(-\frac{J_{w}}{k_{D}}\right)-\frac{J_{w}}{A}}{\left(\frac{B}{A}+\pi_{F, b}\right)}\right]
$$

Eqns. (14)-(16) show that the solute resistivity is, in fact, partly dependent on the mass transfer coefficient of the solute presented in the bulk draw and feed solutions. In other words, the mass transfer of the solute to and from the membrane surface does impact on the behavior of solute molecules inside the porous support layer. This means the increased mass transfer at the porous surface will lead to increased mass transfer within the porous support in both FO and PRO modes. This is well matched with Beavers's study [53] showing that the increase in mass flow rate through the channel is accompanied by an increase in mass flow rate through the permeate wall (e.g. porous membrane).

\subsection{Determination of reflection coefficient and the total resistance of membrane}

Reflection coefficient $\sigma(0<\sigma<1)$ is a measure of the solute reflectivity [54]. $\sigma$ is equal to 0 when the solute and solvent cross the membrane in the same concentration ratio as they are in the adjacent bulk solution [54-56] and is equal to 1 when the solute is completely rejected. In general, $\sigma$ is assumed to be 1 in most studies on FO. However, in reality, no membrane is perfectly selective. Therefore, being able to quantify membrane reflection coefficient could lead to better predictive models of osmotic flux performance and better designs of FO membranes.

In eqn. (12), the osmotic water flux in FO is a function of the water permeability coefficient $\mathrm{A}$, the osmotic pressure difference across the membrane $\Delta \pi_{m}$, and the reverse solute permeability term in the denominator. The reflection coefficient in FO for membranes that are not perfectly selective can therefore be defined as (see Appendix 1 for the derivation):

$$
\sigma=\frac{1}{1+\frac{B}{J_{w}}\left\{\exp \left(\frac{J_{w}}{k_{F}}\right)-\exp \left[-J w\left(\frac{1}{k_{D}}+\frac{S}{D_{D}}\right)\right]\right\}}
$$


By expansion of exponential terms in eqn. (17), we then obtain:

$$
\sigma \approx \frac{1}{1+B\left(\frac{1}{k_{F}}+\frac{1}{k_{D}}+K\right)}=\frac{1 / B}{\frac{1}{B}+\frac{1}{k_{F}}+\frac{1}{k_{D}}+K}
$$

Likewise, the reflection coefficient in PRO can be derived from eqn. (13):

$$
\sigma=\frac{1}{1+\frac{B}{J_{w}}\left\{\exp \left[J_{w}\left(\frac{1}{k_{F}}+\frac{S}{D_{F}}\right)-\exp \left(-\frac{J_{w}}{k_{D}}\right)\right]\right\}}
$$

After expansion, we have:

$$
\sigma \approx \frac{1}{1+B\left(\frac{1}{k_{F}}+\frac{1}{k_{D}}+K\right)}=\frac{1 / B}{\frac{1}{B}+\frac{1}{k_{F}}+\frac{1}{k_{D}}+K}
$$

Appendix A2 shows the error of the approximation by Taylor expansion. In eqns. (18) and (20), the denominator is the sum of the solute resistivity due to (1) membrane selective layer, (2) support structure and (3) mass transfer boundary layers at membranes surfaces. If one analogizes the diffusive flow rate of the solute across the membrane to an electric current through a passive resistor, the total resistance of membrane to solute transport could be defined as the sum of the intrinsic membrane resistance and the solution resistance affected by the convective rate in the bulk fluid [63]. Equations (18) and (20) have similarity to the total solute resistance across the membrane which is defined as,

$$
R=\frac{1}{B}+\frac{1}{k_{F}}+\frac{1}{k_{D}}+K
$$


we can then see that, in osmosis, the membrane reflection coefficient is the percentage of the solute resistivity, $1 / \mathrm{B}$, of the membrane selective layer in the total resistance of the membrane, R. Reflection coefficient is dependent on both membrane characteristics (selectivity, structural parameter) and solution properties (diffusivity, hydrodynamic conditions). This is in good agreement with Anderson and Malone's study showing that reflection coefficient is a function of solute and membrane characteristics [55]. Note that in equation (21), we assumed an insignificant resistance arisen at the membrane-solution interface.

\section{Materials and Methods}

\subsection{Materials}

Sodium chloride was purchased from Fisher Scientific (Pittsburgh, PA). Isopropanol was purchased from J.T. Baker (Center Valley, PA). Water used in this study was ultrapure Milli-Q water produce by a Millipore Integral 10 water system, (Millipore Corporation, Billerica, MA).

\subsection{Membranes}

Two different types of asymmetric membranes specifically designed for osmotically driven membrane processes were used in this study. These were an asymmetric cellulose triacetate membrane embedded with a nonwoven mesh from Hydration Technology Innovations (HTI, Albany, OR) and an early generation of thin-film composite (TFC) membrane from Oasys Water (March 2011, Boston, MA). These two membranes are denoted as HTI and Oasys, respectively. The structure of HTI's cellulose triacetate membrane has been broadly studied and reported elsewhere $[38,57]$. Oasys TFC membrane structure and chemistry are proprietary and have not been widely explored. It is believed to have a thin polyamide selective layer deposited on a porous support which had been casted on a nonwoven backing layer [64].

\subsection{Membrane performance characteristics}




\subsubsection{Intrinsic membrane properties determined by reverse osmosis}

The water permeance of these membranes was measured in a lab scale reverse osmosis testing system at pressures of 10.3, 15.5, 20.7, 25.9 and 31.0 bar $(150,225,300,375$ and $450 \mathrm{psi}$ ) at temperatures of $20^{\circ} \mathrm{C}$ and $40^{\circ} \mathrm{C}$ and am bient $\mathrm{RH}$. Fresh membrane samples were used to determine water permeability coefficients at each of the tested temperatures. Rejection tests were carried out following the measurement of water permeability coefficients at 15.5 bar with a $2000 \mathrm{ppm} \mathrm{NaCl}$ feed at $20^{\circ} \mathrm{C}$ and $40^{\circ} \mathrm{C}$ using a cross flow velocity of $0.25 \mathrm{~m} / \mathrm{s}$. $\mathrm{NaCl}$ rejection was measured using a conductivity. Based upon hydrodynamic conditions of the system and empirical data from Comesana [58] and Lobo [59], intrinsic rejection was determined from a Sherwood number correlation [1]. Intrinsic rejection was used to determine the sodium chloride permeability for this membrane, calculated from the following equation [1].

$$
B=\frac{(1-R) A(\Delta P-\Delta \pi)}{R}=\frac{(1-R) J_{w}}{R}
$$

Here $B$ is the solute permeability coefficient, $R$ is the rejection, $A$ is the water permeability coefficient of the membrane, $\Delta P$ is the transmembrane hydrostatic pressure, $\Delta \pi$ is the transmembrane osmotic pressure, and $\mathrm{J}_{\mathrm{w}}$ is the water flux of the rejection measurement.

\subsubsection{FO/PRO osmotic flux performance}

Cross-flow FO and PRO tests were carried out at $20^{\circ} \mathrm{C}$ and $40{ }^{\circ} \mathrm{C}$ in a lab-scale FO system described elsewhere [25]. No spacers were used. Sodium chloride $(\mathrm{NaCl})$ was used as a model draw and feed solute for this study. Osmotic water flux was measured in both FO (the porous support faces the draw) and PRO (the porous support faces the feed) modes. Zero transmembrane pressure was maintained. For FO, deionized (DI) water was used as the feed solution, whereas $0.5 \mathrm{M}, 1.0 \mathrm{M}$ and $1.5 \mathrm{M} \mathrm{NaCl}$ were used as the draw solutions. For PRO, 0.05 $\mathrm{M}, 0.5 \mathrm{M}$ and $1.0 \mathrm{M} \mathrm{NaCl}$ solutions were used in the feed, while $1.5 \mathrm{M} \mathrm{NaCl}$ solution was fixed as the draw. The feed and draw solutions were maintained the same temperature, pressure and 
cross-flow velocity. Solution properties (e.g. density, viscosity, diffusivity, osmotic coefficient) varying at different concentrations and temperatures were obtained from literature $[58,59]$ and presented in Table 1. Membranes were stored in DI water at $4{ }^{\circ} \mathrm{C}$ prior to testing without pretreatment. Cross-flow velocities used for testing ranged from 10.3 to $20.7,31.0,41.4$ and 46.5 $\mathrm{cm} / \mathrm{s}$ and were maintained for both solutions. The experimental protocol was described in detail in section 2.4 of McCutcheon et al. [38].

\section{Table 1}

\section{Results and Discussion}

\subsection{Membrane permselectivity and osmotic flux performance}

Table 2

Intrinsic water and solute permeance $\mathrm{A}$ and $\mathrm{B}$ of $\mathrm{HTI}$ and Oasys membranes from RO tests are tabulated in Table 2. In general, A and B increased with feed temperature. These values were then substituted into the flux model, eqns. 12 and 13 . Figure 2 illustrates the iteration procedure using a Matlab algorithm.

\section{Figure 2}

Figure 3 shows an increase of osmotic water flux with cross-flow velocity in both FO and PRO experiments. The primary reason for this increased flux is increased mass transfer coefficient and a reduced ECP. Dilution factor of the draw solution and concentration factor of the feed could be considered as well (since crossflow velocity impacts residence time), but these effects were negligible in our system because of the small membrane area and very short residence time (less than 1 second in the cell). In a module, there might be different effects, but our tests were limited to coupons. Figure 3 shows that, both membranes demonstrated significantly enhanced water flux when cross-flow velocities increased from 10.3 to $20.7 \mathrm{~cm} / \mathrm{s}$.

The data shows that the HTI cellulosic membrane has substantially lower flux than the Oasys membrane for both FO and PRO mode. The Oasys membrane performed $2-3$ times 
higher fluxes at the lowest cross-flow velocity than the HTI membrane (Figure 3). This means that all polarization effects will be less severe for the HTI membrane. Figure 3a shows an approximate $40 \%$ increase in water flux over the range of crossflow velocities tested for HTI membrane in both the FO and PRO modes. However, the fluxes for the Oasys membrane were nearly doubled over this same range. Flux is more sensitive to crossflow velocity when the concentration polarization is more severe.

\section{Figure 3}

\subsection{Quantifying Concentration Polarization}

ECP modulus is defined as a ratio of the osmotic pressure measured at the membrane surface to that obtained in the bulk solution [38]. ICP modulus, on the other hand, is the ratio of the osmotic pressure at the support - selective layer interface to that measured at the membrane surface [38]. Dilutive ECP/ICP modulus is between 0 and 1 whereas concentrative ECP/ICP modulus is greater than 1 [38]. The farther these ratios are from the value of 1 is indicative of more severe polarization.

\subsubsection{External concentration polarization on the porous side $\left(E C P^{p}\right)$ of $E O$ membranes}

\section{Figure 4}

Figure 4 shows the dilutive and concentrative ECP moduli [38] obtained from FO and PRO tests at different draw and feed concentrations, respectively, for HTI and Oasys membranes. ECP moduli were calculated from the exponential function of ratio of water flux to mass transfer coefficient [38, 42]. Results show that these moduli deviate from 1 substantially in both cases, and therefore, should not be neglected in the prediction of FO membrane performance (as they are currently). The Oasys TFC membrane shows a more severe ECP compared to the HTI membrane due to the fact that the membrane performs at higher water flux at the same conditions. 


\subsubsection{Internal concentration polarization (ICP)}

\subsubsection{Impacts of Crossflow Velocity on ICP}

\section{Figure 5}

Figure 5 shows the dilutive ICP modulus in the FO mode for both membranes calculated based on eqn. (15) listed elsewhere [38]. As noted by the increasing modulus, ICP became less severe with increasing cross-flow velocity. This is counter to the commonly belief that ICP is an unstirred boundary layer inside the porous support and, therefore, cannot be mitigated by hydrodynamic conditions $[1,39,60]$. In fact, crossflow velocity induces mixing in the porous support layer, especially for well-designed membranes that have thin and highly porous support layers. Such an effect was previously observed by Beavers and Joseph, where an increase in mass flow rate through the channel is accompanied by an increase in mass flow rate through a porous wall (e.g. porous membrane) [53]. As shown in Figure 5b, shear effects are transmitted into the body of the porous materials through a boundary layer region [53]. It indicates that increasing the cross-flow velocity not only thins the ECP ${ }^{p}$ boundary layer, it changes the slip velocity of fluid at membrane support layer surface. This impacts mass transfer into the support layer itself, especially at higher crossflow velocities. Other properties, such as high surface porosity or roughness may intensify this effect. Note that both $\mathrm{HTI}$ and Oasys membrane supports may have relatively high surface roughness and high porosity due to the large average pore diameter of the support layer (i.e. the embedded mesh and polyester non-woven fabric for 
$\mathrm{HTI}$ and Oasys, respectively). Results show that the HTI and Oasys membranes behaved differently with increased cross-flow velocity. For the Oasys membrane, dilutive ICP modulus increased substantially when velocity increased from 10.3 to $20.7 \mathrm{~cm} / \mathrm{s}$ and then plateaued. On the other hand, for the HTI membrane, ICP modulus increased gradually and continuously across the full range of cross-flow velocities considered. These results indicate that, for the more optimized support structure of the Oasys membrane, ICP can be diminished at high crossflow velocity, though this benefit has diminishing returns at even higher velocity. This is not the case for the asymmetric $\mathrm{HTI}$ membrane structure which consists of a polyester mesh embedded in a porous polymer layer. This denser structure resists internal mixing and thus the benefits are improved throughout a wide range of crossflow velocities.

\subsubsection{Impact of draw and feed concentrations on ICP modulus}

The impact of draw and feed concentration in FO and PRO has long been studied across the osmotic separations literature. However, little has been done with examining the impact of these solution concentrations with relation to concentration polarization both inside and outside of the membrane structure. Our results (Figure 6) definitively show that ICP modulus is more severe with increased draw concentration in FO and decreased feed concentration in PRO. Also, ICP impacted the Oasys membrane more intensely than the HTI membrane, especially in FO mode. This is largely due to the substantially higher fluxes generated with the Oasys Membrane.

\section{Figure 6}

\subsubsection{Comparison with previous flux models}

Figure 6 also compares our work to earlier McCutcheon's and Yip-Tiraferri's flux models. This work shows a less severe ICP since it no longer incorporates ECP along the support layer side of the membrane $\left(\mathrm{ECP}^{\mathrm{p}}\right)$. Our data shows that these earlier estimates led to an 


\subsection{Lost driving force caused by concentration polarization}

Figure 7

Figure 8

While the modulus is an important value when describing boundary layer phenomenon with FO, it may not be representative of the true impact of the polarization on membrane performance. For example, a high concentrative modulus may have little impact on the driving force if the solute concentration is very low. We therefore must consider the real impact on driving force caused by concentration polarization. Figures 7 and 8 show the lost driving force caused by concentration polarizations in FO and PRO modes, respectively, as a percentage of total lost driving force. In FO, although ICP is responsible for most of the loss of driving force, $\mathrm{ECP}^{\mathrm{p}}$ is responsible for $\sim 20 \%$ and $\sim 40 \%$ of the driving force loss for the $\mathrm{HTI}$ and Oasys membranes, respectively. Since DI water was used as the feed solution, ECP on the feed was negligible and therefore not visible in the graph (Figure 7). In the PRO mode, the ICP contributed less to the reduction in driving force. Instead, ECP (on the selective side) significantly reduced the driving force (up to $40 \%$ for the Oasys membrane). Although ECP ${ }^{p}$ was less pronounced, it was non-negligible ( $8 \%$ for the $\mathrm{HTI}$ and $\sim 20 \%$ for the Oasys membrane). In all cases, the Oasys TFC membrane support appeared to be significantly impacted by the ECP boundary layers at membrane surfaces. This is expected given the high flux of these membranes. The HTI membrane performance was severely influenced by the ICP within the membrane support structure. 


\subsection{Solute resistivity, $\mathrm{K}$}

Figure 9

Figure 9 shows that solute resistivity, $\mathrm{K}$, obtained from $\mathrm{FO}$ was higher than $\mathrm{PRO}$ due to the more severe ICP within the support. As commonly defined, $\mathrm{K}$ is an intrinsic property of membrane support for a given draw solution (at a specific diffusivity). It is, therefore, believed to be unaffected by hydrodynamic conditions at the surface of the support layer. However, in Figure $9, \mathrm{~K}$ is shown to decrease with increasing cross-flow velocity in both membranes and orientations. These results are in agreement with equations (14) and (16) showing that $\mathrm{K}$ is a function of mass transfer coefficient, $k$, at the surface of the support. As mentioned, tangential cross-flow velocity can partially induce mixing within the porous support leading to increased effective diffusivity of solutes (Reynolds numbers and mass transfer coefficients in the draw and the feed are tabulated in Table 3). As such, the porous support is no longer an unstirred zone and the original assumptions used in defining solute resistivity are no longer valid [39].

\section{Table 3}

\subsection{The true structural parameter}

In general, empirical structural parameter measured in the PRO mode was smaller than from FO (Figure 10). Results show that structural parameters obtained from McCutcheon's and Yip-Tiraferri's flux models were higher than those calculated from this study by $15-45 \%$. Note that unlike many previous models, we took into account the difference of mass transfer coefficients between the feed and the draw sides, e.g. $k_{F}$ and $k_{D}$, respectively. Also, dependences of the solution physical properties (e.g. density, viscosity, diffusivity, etc.) on the testing conditions (e.g. concentration, temperature) were included in our study.

Figure 10

Furthermore, calculated structural parameters decreased with cross-flow velocity. Originally, we had hoped that proper accounting of the mass transfer resistance would have 
resulted in the $S$ parameter being calculated as being the same regardless of the testing conditions. However, due to the mixing induced in the support layer caused by increased tangential flow as suggested in Figure $5 \mathrm{~b}$, the underlying assumption of a stagnant layer in the support layer is incorrect. This means that the "no slip" condition (where crosslflow is zero) is actually within the support layer and this reduces the thickness of the support layer, perhaps by a substantial amount. Thus, since the model assumes "no mixing" in the support layer, and mixing that does occur will force the model to output lower structural parameters to compensate.

Figure 11

Likewise, the structural parameter has been theoretically derived as an effective thickness of the membrane support and should therefore be independent of operating conditions such as membrane orientation, solution concentration, and temperature. Park et al. [48] presented a numerical model based on finite element method to determine a relatively constant membrane structural parameter in FO. However, as empirical S values have been broadly estimated and reported using common flux models [21, 38, 52], understanding on how and why the value of this parameter changes with testing conditions is imperative. This is even more important considering few groups around the world use a standardized method for measuring structural parameter [61].

In fact, changes in empirical $\mathrm{S}$ with testing conditions partly dictate transport behaviors of solute within the membrane structure. Figure 11 shows structural parameters of the HTI and Oasys membranes calculated across different operating temperatures and draw and feed concentrations in FO and PRO modes using our model. In general, we saw relatively constant structural parameter for the Oasys TFC membrane over a broad range of solutions conditions. However, structural parameter values for the HTI membranes changed substantially with varying testing conditions. The HTI membrane $S$ values changed with increased draw concentration in FO while they gradually decreased with feed concentration in PRO. 


\subsection{Total resistance of membranes to solute transport, $\mathbf{R}$}

As defined in eqn. (21), total resistance to solute transport $(R)$ is the sum of all resistivity that solute encounters when transporting across the membrane from the bulk draw to the bulk feed solutions. These include solute resistivity due to membrane selective layer (1/B), the support layer $(K)$ and the mass transfer boundary layers at membrane surfaces $\left(1 / k_{D}\right.$ and $\left.1 / k_{F}\right)$. $\mathrm{R}$ can be considered as a combination of membrane resistance and solution resistance to ions transport (see Figure 1). Total resistance is impacted by membrane structure and testing conditions (e.g. cross-flow velocity, temperature). It is, therefore, necessary to improve membrane design to obtain a minimal total resistance to solute transport toward the selective layer while also adjusting our testing and data analysis protocols to ensure that we are accurately attributing performance metrics to the appropriate membrane property.

Figure 12

Figure 12 shows that total solute resistance of the Oasys TFC membrane is less than that of $\mathrm{HTI}$ asymmetric membrane due mainly to its smaller solute resistivity $\mathrm{K}$. In addition, increasing cross-flow velocity reduced total membrane solute resistance because it increased mass transfer at membrane surfaces, thinned the ECP boundary layers, and reduced ICP. However, the insignificant decrease of total resistance with further increasing cross-flow velocities indicates that the membrane intrinsic parameters affect solute resistance more than process hydrodynamics. Furthermore, $\mathrm{R}$ was found to decrease substantially with increasing temperature. Raising testing temperature from 20 to $40^{\circ} \mathrm{C}$ led to increases in solute diffusivity (by $\sim 35 \%$, table 1 ), mass transfer coefficients $k_{D}$ and $k_{F}$ as a function of crossflow velocity (by $\sim 12-40 \%$ ), and the solute permeability coefficient B (by $\sim 6 \%$ for the HTI membrane, $\sim 30 \%$ for the Oasys membrane, table 2). Therefore, the decrease of $R$ with temperature was more pronounced for the Oasys membrane ( 33\%) than the HTI membrane ( 10\%). 


\subsection{Reflection coefficient}

In eqns. (18) or (20), we defined reflection coefficient, $\sigma(0<\sigma<1)$, as the ratio of the solute resistivity of the membrane selective layer and the total resistance to solute transport, $R$. It is inversely proportional to total resistance and is, therefore, determined by both membrane characteristics (selectivity, structural parameter) and solute behaviors (diffusivity, mass transfer coefficient). Table 4 tabulates reflection coefficient of Oasys and HTI membranes at different testing conditions (e.g. membrane orientation, draw and feed concentrations, and cross-flow velocity). In general, the HTI membrane, with its smaller B, was more selective than the Oasys TFC membrane.

\section{Table 4}

It is hypothesized that solute behaviors are dependent on the coupling effects of (1) the tangential fluid flows at membrane surfaces, (2) the convective water flow and (3) the diffusive solute flow across the membrane. A change in intensity of any flow would impact the residence time of solutes in the vicinity of membrane surfaces. The longer the solutes stay at membrane surfaces, the more likely these molecules would partition to the selective layers and diffuse across the membranes. As such, membranes become more selective at shorter solute residence time. In FO, the increased cross-flow velocity along with increased mixing and enhanced convective water flux would swiftly sweep the solutes away from membrane surfaces. Due to the reduced residence time, solutes had less chance to partition and penetrate across the membrane. Therefore, membranes tend to be more selective at high water flux (i.e. high cross-flow velocity and high draw concentration).

On the other hand, in PRO, the convective water flux, while carrying solute molecules from the bulk feed, is driven toward the support - selective layer interface. As a result, lower water flux would reduce the chances of solutes to stay in the vicinity of selective layer surface to diffuse through. As the feed concentration increased from $0.05 \mathrm{M}$ to $1 \mathrm{M} \mathrm{NaCl}$, the osmotic water flux reduced significantly leading to an increased reflection coefficient. Namely, the 
membrane was more selective with increased feed concentration. However, in PRO, when mixing is introduced at high cross-flow velocity, there is a tradeoff between mixing intensity and the convective water flux. Increased cross-flow velocity led to enhanced osmotic water flux. However, this enhancement of water flux was not sufficient to surpass the mixing intensity generated by the tangential fluid flow. It resulted in a shorter residence time for solutes to stay within the porous support and thus increased reflection coefficient at high cross-flow velocity.

\section{Conclusions}

As noted throughout this paper, there are numerous complexities associated with understanding mass transfer during osmotic flux across asymmetric membranes. While internal concentration polarization has been studied in detail for some time, rarely has it been placed in context with all other resistances for solute flux (which ultimately dictates driving force in osmosis). The model introduced here allows for a full accounting, and deconvolution, of all resistances present for solute transport during osmosis. This allows for a more accurate calculation of typical membrane design metrics, such as structural parameter. Accuracy in these calculations is critical if membrane and system designers are expected to increase process efficiency. If, for instance as this study shows, structural parameter is overpredicted, then designers will wrongly focus on membrane design, only to find out later that hydrodynamics is more important than previously thought. This overprediction becomes more of an issue as better membranes are made (as has been seen recently by numerous academic groups and companies around the world). Accurate accounting of resistances through well-developed models that are verified by experiments and analysis of membrane structure will be essential as forward osmosis and its sibling processes gain their first footholds into the commercial sector and thereby require extensive optimization.

\section{Acknowledgements}


The authors acknowledge funding and support from the National Science Foundation (CBET \# 1067564), Oasys Water, the Department of Energy (DE-EE00003226), and the Environmental Protection Agency STAR Program (R834872). The authors also thank support from the AMTA-NWRI Membrane Technology Fellowship and the National Science Foundation GK-12 Program. We thank Hydration Technologies Innovations and Oasys Water for providing membranes for this study.

\section{Nomenclature}

$$
\begin{aligned}
& \mathrm{ECP}^{\mathrm{s}} \quad \text { external concentration polarization, at the selective layer surface } \\
& \mathrm{ECP}^{\mathrm{p}} \quad \text { external concentration polarization, at the porous support } \\
& \text { cECP, dECP concentrative/dilutive external concentration polarization } \\
& J_{w} \quad \text { osmotic water flux }\left(\text { gal.ft }^{-2} \text { day }^{-1}\right) \\
& J_{s}{ }^{a} \quad \text { reverse salt flux across the selective layer (gal.ft }{ }^{-2} \text { day }^{-1} \text { ) } \\
& J_{s}{ }^{d}, J_{s}{ }^{f} \quad \text { reverse salt flux across the porous support, facing against the } \\
& \text { draw/feed solution, respectively (gal.ft } \mathrm{ft}^{-2} \mathrm{day}^{-1} \text { ) } \\
& \text { A water permeability coefficient }\left(\text { gal. }^{-2} \mathrm{day}^{-1} \mathrm{psi}^{-1}\right) \\
& \text { B solute permeability coefficient (gal. } \mathrm{ft}^{-2} \mathrm{day}^{-1} \text { ) } \\
& \sigma \quad \text { reflection coefficient } \\
& \Delta \pi_{m} \quad \text { osmotic pressure difference across the selective layer (bar) } \\
& \pi_{D, m}, \pi_{F, m} \quad \text { osmotic pressure of the draw/feed solution, at two sides of } \\
& \text { selective layer (bar) } \\
& \pi_{D, b}, \pi_{F, b} \quad \text { osmotic pressure of the draw/feed solution, in the bulk (bar) }
\end{aligned}
$$


osmotic pressure of the draw/feed solution, at the surface of the porous support (bar)

$\Delta P$

$\Delta C_{m}$

$C_{D, m}, C_{F, m}$

$C_{D, b}, C_{F, b}$

$C_{D, i}, C_{F, i}$

$D$

$D_{s}$

$D_{D}, D_{F}$

$x, z$

$C(x), C(z)$

$\varepsilon$

$\tau$

$t_{s}$

$\delta_{D}, \delta_{F}$

$S$

$k_{D}, k_{F}$ transmembrane hydraulic pressure difference (bar)

concentration gradient across the selective layer ( $\mathrm{mol} / \mathrm{l})$

concentration of the draw/feed solution, at two sides of selective

layer $(\mathrm{mol} / \mathrm{l})$

concentration of the draw/feed solution, in the bulk (mol/l)

concentration of the draw/feed solution, at the surface of the

porous support (mol/l)

solute diffusion coefficient $\left(\mathrm{m}^{2} / \mathrm{s}\right)$

solute diffusion coefficient inside the support layer $\left(\mathrm{m}^{2} / \mathrm{s}\right)$

solute diffusion coefficient in the bulk draw/feed $\left(\mathrm{m}^{2} / \mathrm{s}\right)$

coordinates perpendicular to membrane axis

solute concentration varies with positions $(\mathrm{mol} / \mathrm{l})$

porosity of membrane support

tortuosity of membrane support

thickness of the membrane support $(\mu \mathrm{m})$

thickness of the boundary layer at membrane surfaces, facing against the draw/feed $(\mu \mathrm{m})$

structural parameter of the support layer $(\mu \mathrm{m})$

mass transfer coefficient of the draw/feed $(\mathrm{m} / \mathrm{s})$ 


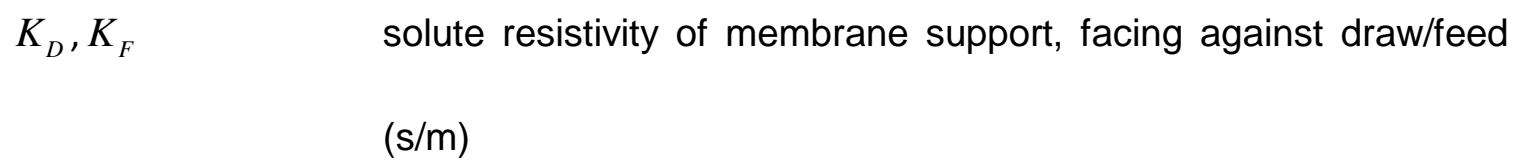

R

membrane total resistance to solute transport $(\mathrm{s} / \mathrm{m})$ 


\section{References}

1. Cath, T.Y., A.E. Childress, and M. Elimelech, Forward Osmosis: Principles, Applications, and Recent Developments. Journal of Membrane Science, 2006. 281: p. 70-87.

2. Zhao, S., L. Zou, C.Y. Tang, and D. Mulcahy, Recent developments in forward osmosis: Opportunities and challenges. Journal of Membrane Science, 2012. 396: p. 1-21.

3. McGinnis, R.L. and M. Elimelech, Global Challenges in Energy and Water Supply: The Promise of Engineered Osmosis. Environmental Science \& Technology, 2008. 42: p. 8625-8629.

4. Cath, T.Y., N.T. Hancock, C.D. Lundin, C. Hoppe-Jones, and J.E. Drewes, A multi-barrier osmotic dilution process for simultaneous desalination and purification of impaired water. Journal of Membrane Science, 2010. 362: p. 417-426.

5. Linares, R.V., V. Yangali-Quintanilla, Z. Li, and G. Amy, Rejection of micropollutants by clean and fouled forward osmosis membrane. Water Research, 2011. 45: p. 6737-6744.

6. Loo, S.-L., A.G. Fane, W.B. Krantz, and T.-T. Lim, Emergency water supply: A review of potential technologies and selection criteria. Water Research, 2012. 46: p. 3125-3151.

7. Holloway, R.W., A.E. Childress, K.E. Dennett, and T.Y. Cath, Forward osmosis for concentration of anaerobic digester centrate. Water Research, 2007. 41: p. 4005-4014.

8. Sant'Anna, V., L.D.F. Marczak, and I.C. Tessaro, Membrane Concentration of Liquid Foods by Forward Osmosis: Process and Quality View. Journal of Food Engineering, 2012. 111: p. 483-489.

9. Nayak, C.A. and N.K. Rastogi, Forward osmosis for the concentration of anthocyanin from Garcinia indica Choisy. Separation and Purification Technology, 2010. 71: p. 144-151.

10. Kravath, R.E. and J.A. Davis, Desalination of sea water by direct osmosis. Desalination, 1975. 16: p. 151-155.

11. Kessler, J.O. and C.D. Moody, Drinking water from sea water by forward osmosis. Desalination, 1976. 18: p. 297-306.

12. Yangali-Quintanilla, V., Z. Li, R. Valladares, Q. Li, and G. Amy, Indirect Desalination of Red Sea Water with Forward Osmosis and Low Pressure Reverse Osmosis for Water Reuse. Desalination, 2011. 280: p. 160-166.

13. Achilli, A., T.Y. Cath, and A.E. Childress, Power generation with pressure retarded osmosis: An experimental and theoretical investigation. Journal of Membrane Science, 2009. 343: p. 42-52.

14. Achilli, A. and A.E. Childress, Pressure retarded osmosis: From the vision of Sidney Loeb to the first prototype installation - Review. Desalination, 2010. 261(3): p. 205-211.

15. Isaacs, J.D. and R.J. Seymour, The Ocean as a Power Resource. Intern. J. Environmental Studies, 1973. 4: p. 201-205.

16. Logan, B.E. and M. Elimelech, Membrane-based Processes for Sustainable Power Generation Using Water. Nature, 2012. 4888: p. 313-319.

17. McGinnis, R., A. Mandell, and R. Stover, Osmotic Heat Engine, W.I.P. Organization, Editor. 2013: WO 2013/033082 A1.

18. McGinnis, R.L. and A. Mandell, Utility Scale Osmotic Grid Storage, U.S.P.A. Publication, Editor. 2010: US 2010/0183903 A1.

19. Ramon, G.Z., B.J. Feinberg, and E.M.V. Hoek, Membrane-based Production of Salinity-gradient Power. Energy \& Environmental Science, 2011. 4: p. 4423.

21. Yip, N.Y., A. Tiraferri, W.A. Phillip, J.D. Schiffman, L.A. Hoover, Y.C. Kim, and M. Elimelech, ThinFilm Composite Pressure Retarded Osmosis Membranes for Sustainable Power Generation from Salinity Gradients. Environmental Science \& Technology, 2011. 45(10): p. 4360-4369.

22. Yip, N.Y., A. Tiraferri, W.A. Phillip, J.D. Schiffman, and M. Elimelech, High Performance Thin-Film Composite Forward Osmosis Membrane. Environmental Science \& Technology, 2010. 44: p. 3812-3818. 
23. Tiraferri, A., N.Y. Yip, W.A. Phillip, J.D. Schiffman, and M. Elimelech, Relating Performance of Thin-Film Composite Forward Osmosis Membranes to Support Layer Formation and Structure. Journal of Membrane Science, 2011. 367: p. 340-352.

24. Bui, N.-N. and J.R. McCutcheon, Hydrophilic Nanofibers as New Supports for Thin Film Composite Membranes for Engineered Osmosis. Environmental Science \& Technology, 2013. 47: p. 17611769.

25. Bui, N.-N., M.L. Lind, E.M.V. Hoek, and J.R. McCutcheon, Electrospun nanofiber supported thin film composite membranes for engineered osmosis. Journal of Membrane Science, 2011. 385386: p. 10-19.

26. Huang, L., N.-N. Bui, M.T. Meyering, T.J. Hamlin, and J.R. McCutcheon, Novel Hydrophilic Nylon 6,6 Microfiltration Membrane Supported Thin Film Composite Membranes for Engineered Osmosis. Journal of Membrane Science, 2013. 437: p. 141-149.

27. Qi, S., C.Q. Qiu, Y. Zhao, and C.Y. Tang, Double-skinned forward osmosis membranes based on layer-by-layer assembly-FO performance and fouling behavior. Journal of Membrane Science, 2012. 405-406: p. 20-29.

28. Widjojo, N., T.-S. Chung, M. Weber, C. Maletzko, and V. Warzelhan, The role of sulphonated polymer and macrovoid-free structure in the support layer for thin-film composite (TFC) forward osmosis (FO) membranes. Journal of Membrane Science, 2011. 383: p. 214-223.

29. Wang, R., L. Shi, C.Y. Tang, S. Chou, C. Qiu, and A.G. Fane, Characterization of novel forward osmosis hollow fiber membranes. Journal of Membrane Science, 2010. 355: p. 158-167.

30. Song, X., Z. Liu, and D.D. Sun, Energy Recovery from Concentrated Seawater Brine by Thin-film Nanofiber Composite Pressure Retarded Osmosis Membranes with High Power Density. Energy \& Environmental Science, 2013. 6: p. 1199.

31. Arena, J.T., B. McCloskey, B.D. Freeman, and J.R. McCutcheon, Surface modification of thin film composite membrane support layers with polydopamine: Enabling use of reverse osmosis membranes in pressure retarded osmosis. Journal of Membrane Science, 2011. 375: p. 55-62.

32. Bui, N.-N. and J.R. McCutcheon, Nanofiber Supported Thin-film Composite Membrane for Pressure Retarded Osmosis. Environmental Science and Technology, 2014. 48: p. 4129-4136.

33. Ling, M.M. and T.-S. Chung, Desalination process using super hydrophilic nanoparticles via forward osmosis integrated with ultrafiltration regeneration. Desalination, 2011. 278: p. 194202.

34. Stone, M.L., C. Rae, F.F. Stewart, and A.D. Wilson, Switchable Polarity Solvents as Draw Solutes for Forward Osmosis. Desalination, 2013. 312: p. 124-129.

35. Ge, Q., J. Su, G.L. Amy, and T.-S. Chung, Exploration of polyelectrolytes as draw solutes in forward osmosis processes. Water Research, 2012. 46: p. 1318-1326.

36. Stone, M.L., A.D. Wilson, M.K. Harrup, and F.F. Stewart, An Initial Study of Hexavalent Phosphazene Salts as Draw Solutes in Forward Osmosis. Desalination, 2013. 312: p. 130-136.

37. Achilli, A., T.Y. Cath, and A.E. Childress, Selection of inorganic-based draw solutions for forward osmosis applications. Journal of Membrane Science, 2010. 364(1-2): p. 233-241.

38. McCutcheon, J.R. and M. Elimelech, Influence of concentrative and dilutive internal concentration polarization on flux behavior in forward osmosis. Journal of Membrane Science, 2006. 284: p. 237-247.

39. Lee, K.L., R.W. Baker, and H.K. Lonsdale, Membranes for power generation by pressure-retarded osmosis. Journal of Membrane Science, 1981. 8: p. 141-171.

40. Loeb, S., L. Titelman, E. Korngold, and J. Freiman, Effect of porous support fabric on osmosis through a Loeb-Sourirajan type asymmetric membrane. Journal of Membrane Science, 1997. 129: p. 243-249. 
41. Tan, C.H. and H.Y. Ng, Modified Models to Predict Flux Behavior in Forward Osmosis in Consideration of External and Internal Concentration Polarizations. Journal of Membrane Science, 2008. 324: p. 209-219.

42. McCutcheon, J.R. and M. Elimelech, Modeling Water Flux in Forward Osmosis: Implications for Improved Membrane Design. American Institute of Chemical Engineers Journal, 2007. 53: p. 1736-1744.

43. Phillip, W.A., J.S. Yong, and M. Elimelech, Reverse Draw Solute Permeation in Forward Osmosis: Modeling and Experiments. Environmental Science \& Technology, 2010. 44(13): p. 5170-5176.

44. Yaroshchuk, A., Influence of osmosis on the diffusion from concentrated solutions through composite/asymmetric membranes: Theoretical analysis. Journal of Membrane Science, 2010. 355: p. 98-103.

45. Li, W., Y. Gao, and C.Y. Tang, Network Modeling for Studying the Effect of Support Structure on Internal Concentration Polarization during Forward Osmosis: Model Development and Theoretical Analysis with FEM. Journal of Membrane Science, 2011. 379: p. 307-321.

46. Tan, C.H. and H.Y. Ng, Revised External and Internal Concentration Polarization Models to Improve Flux Prediction in Forward Osmosis Process. Desalination, 2013. 309: p. 125-140.

47. Shakaib, M., S.M.F. Hasani, and M. Mahmood, CFD Modeling for Flow and Mass Transfer in Spacer-obstructed Membrane Feed Channels. Journal of Membrane Science, 2009. 326: p. 270284.

48. Park, M., J.J. Lee, S. Lee, and J.H. Kim, Determination of a constant membrane structure parameter in forward osmosis processes. Journal of Membrane Science, 2011. 375: p. 241-248.

49. Jung, D.H., J. Lee, D.Y. Kim, Y.G. Lee, M. Park, S. Lee, D.R. Yang, and J.H. Kim, Simulation of forward osmosis membrane process: Effect of membrane orientation and flow direction of feed and draw solutions. Desalination, 2011. 277: p. 83-91.

50. Gruber, M.F., C.J. Johnson, C.Y. Tang, M.H. Jensen, L. Yde, and C. Hélix-Nielsen, Computational fluid dynamics simulations of flow and concentration polarization in forward osmosis membrane systems. Journal of Membrane Science, 2011. 379: p. 488-495.

51. Mehta, G.D. and S. Loeb, Internal Polarization in the Porous Substructure of a Semipermeable Membrane under Pressure-retarded Osmosis. Journal of Membrane Science, 1978. 4: p. 261-265.

52. Tiraferri, A., N.Y. Yip, A.P. Straub, S.R.-V. Castrillon, and M. Elimelech, A Method for the Simultaneous Determination of Transport and Structural Parameters of Forward Osmosis Membranes. Journal of Membrane Science, 2013. 444: p. 523-538.

53. Beavers, G.S. and D.D. Joseph, Boundary Conditions at a Naturally Permeable Wall. J. Fluid Mech., 1967. 30: p. 197-207.

54. Pusch, W. and R. Riley, Relation Between Salt Rejection $r$ and Reflection Coefficient $\sigma$ of Asymmetric Cellulose Acetate Membranes. Desalination, 1974. 14: p. 389-393.

55. Anderson, J.L. and D.M. Malone, Mechanism of Osmotic Flow in Porous Membranes. Biophysical Journal, 1974. 14: p. 957-982.

56. Su, J. and T.-S. Chung, Sublayer structure and reflection coefficient and their effects on concentration polarization and membrane performance in FO processes. Journal of Membrane Science, 2011. 376: p. 214-224.

57. McCutcheon, J.R. and M. Elimelech, Influence of membrane support layer hydrophobicity on water flux in osmotically driven membrane processes. Journal of Membrane Science, 2008. 318: p. 458-466.

58. Comesana, J.F., J.J. Otero, E. Camesella, and A. Correa, Densities and Viscosities of Ternary Systems of Water, Fructose, Sodium Chloride from 20 to 40 oC. Journal of Chemical Engineering Data, 2001. 46: p. 1153-1155. 
59. Lobo, V.M.M., Mutual Diffusion Coefficients in Aqueous Electrolyte Solutions. Pure and Applied Chemistry, 1993. 65: p. 2613-2640.

60. Gray, G.T., J.R. McCutcheon, and M. Elimelech, Internal concentration polarization in forward osmosis: role of membrane orientation. Desalination, 2006. 197: p. 1-8.

61. Cath, T.Y., M. Elimelech, J.R. McCutcheon, R.L. McGinnis, A. Achilli, D. Anastasio, A.R. Brady, A.E. Childress, I.V. Farr, N.T. Hancock, J. Lampi, L.D. Nghiem, M. Xie, and N.Y. Yip, Standard Methodology for Evaluating Membrane Performance in Osmotically Driven Membrane Processes. Desalination, 2013. 312: p. 31-38.

62. Nagy, E., A General, Resistance-in-series, Salt-and Water Flux Models for Forward Osmosis and Pressure-retarded Osmosis for Energy Generation. Journal of Membrane Science, 2014. 460: p71-81.

63. Malone, D. M., Anderson J. L., Diffusional Boundary-layer Resistance for Membranes with Low Porosity. AIChE Journal, 1977. 23: p177-184.

64. McGinnis, R., McGurgan, G., Forward Osmosis Membrane, United States Patent. 2012: US 8,181,794 B2. 


\section{Tables and Figures}

Table 1 - Physical properties of fluids and mass transfer coefficient $k$ of the draw and the feed at different temperature and concentrations $[58,59]$.

\begin{tabular}{|c|c|c|c|c|c|c|}
\hline \multicolumn{6}{|c|}{ Physical properties of $\mathrm{NaCl}$ solutions } \\
\hline & \multicolumn{2}{|c|}{$\begin{array}{c}\text { Density } \\
\left(\mathrm{kg} / \mathrm{m}^{3}\right)\end{array}$} & \multicolumn{2}{|c|}{$\begin{array}{c}\text { Viscosity } / 10^{-3} \\
(\mathrm{mPa})\end{array}$} & $\begin{array}{c}\text { Diffusivity } / 10^{-9} \\
\left(\mathrm{~m}^{2} / \mathrm{s}\right)\end{array}$ \\
\hline $\begin{array}{c}\text { Concentration } \\
(\mathrm{M})\end{array}$ & $20^{\circ} \mathrm{C}$ & $40^{\circ} \mathrm{C}$ & $20^{\circ} \mathrm{C}$ & $40^{\circ} \mathrm{C}$ & $20^{\circ} \mathrm{C}$ & $40^{\circ} \mathrm{C}$ \\
\hline 0 & 998.2 & 992.2 & 1.002 & 0.653 & 1.383 & 1.715 \\
\hline 0.05 & 1000.3 & 994.22 & 1.007 & 0.656 & 1.329 & 2.0414 \\
\hline 0.5 & 1018.5 & 1011.8 & 1.047 & 0.682 & 1.281 & 2.049 \\
\hline 1 & 1037.8 & 1030.4 & 1.092 & 0.716 & 1.301 & 2.077 \\
\hline 1.5 & 1056.4 & 1048.4 & 1.144 & 0.753 & 1.323 & 2.123 \\
\hline
\end{tabular}


Table 2 - Membranes permselectivity tested in $\mathrm{RO}$ at $20{ }^{\circ} \mathrm{C}$ and $40{ }^{\circ} \mathrm{C}$. Water permeability coefficient, A, was obtained at pressures from 150 to 450 psi. Solute permeability coefficient, B was determined at 225 psi, using 2000 ppm NaCl feed solution.

\begin{tabular}{|c|cc|cc|}
\hline & \multicolumn{2}{|c|}{ HTI } & \multicolumn{2}{c|}{ Oasys } \\
\hline $\begin{array}{c}\text { Temperature } \\
\left({ }^{\circ} \mathrm{C}\right)\end{array}$ & $\begin{array}{c}\mathrm{A} \\
(\mathrm{LMH} / \mathrm{bar})\end{array}$ & $\begin{array}{c}\mathrm{B} \\
(\mathrm{LMH})\end{array}$ & $\begin{array}{c}\mathrm{A} \\
(\mathrm{LMH} / \mathrm{bar})\end{array}$ & $\begin{array}{c}\mathrm{B} \\
(\mathrm{LMH})\end{array}$ \\
\hline 20 & $0.627 \pm 0.108$ & $0.733 \pm 0.079$ & $3.920 \pm 0.178$ & $1.346 \pm 0.130$ \\
\hline 40 & $0.804 \pm 0.027$ & $0.777 \pm 0.020$ & $5.439 \pm 0.091$ & $1.939 \pm 0.066$ \\
\hline
\end{tabular}


Table 3 - Reynolds numbers and predicted mass transfer coefficients $\mathrm{k}_{\mathrm{D}}, \mathrm{k}_{\mathrm{F}}$, at different testing conditions

\begin{tabular}{|c|c|c|c|c|c|c|c|c|c|c|c|c|c|}
\hline \multicolumn{4}{|c|}{ Cross-flow velocity $(\mathrm{cm} / \mathrm{s})$} & \multicolumn{2}{|c|}{10.3} & \multicolumn{2}{|c|}{20.7} & \multicolumn{2}{|c|}{31.0} & \multicolumn{2}{|c|}{41.4} & \multicolumn{2}{|c|}{46.5} \\
\hline Mode & $\begin{array}{c}\text { Temperature } \\
\left({ }^{\circ} \mathrm{C}\right)\end{array}$ & Solutions & $\begin{array}{c}\mathrm{NaCl} \\
\text { Concentration } \\
\text { (M) }\end{array}$ & $\operatorname{Re}$ & $\begin{array}{l}k^{*} 10^{5} \\
(\mathrm{~m} / \mathrm{s})\end{array}$ & Re & $\begin{array}{l}k^{*} 10^{5} \\
(\mathrm{~m} / \mathrm{s})\end{array}$ & $\operatorname{Re}$ & $\begin{array}{l}k^{*} 10^{5} \\
(\mathrm{~m} / \mathrm{s})\end{array}$ & $\operatorname{Re}$ & $\begin{array}{l}k^{*} 10^{5} \\
(\mathrm{~m} / \mathrm{s})\end{array}$ & $\operatorname{Re}$ & $\begin{array}{l}k^{*} 10^{5} \\
(\mathrm{~m} / \mathrm{s})\end{array}$ \\
\hline \multirow{8}{*}{ FO } & \multirow{4}{*}{20} & \multirow{3}{*}{ Draw } & 0.5 & 456.7 & 1.388 & 913.4 & 1.745 & 1370.2 & 1.995 & 1826.9 & 2.193 & 2055.2 & 2.705 \\
\hline & & & 1.0 & 446.2 & 1.403 & 892.4 & 1.763 & 1338.6 & 2.016 & 1784.8 & 2.216 & 2007.9 & 2.718 \\
\hline & & & 1.5 & 433.6 & 1.419 & 867.1 & 1.783 & 1300.6 & 2.038 & 1734.2 & 2.241 & 1951.0 & 2.330 \\
\hline & & Feed & DI water & 467.7 & 1.461 & 935.4 & 1.837 & 1403.2 & 2.100 & 1870.9 & 2.309 & 2104.7 & 2.864 \\
\hline & \multirow{4}{*}{40} & \multirow{3}{*}{ Draw } & 0.5 & 696.5 & 1.902 & 1393.1 & 2.391 & 2089.6 & 2.733 & 2786.2 & 3.846 & 3134.4 & 4.122 \\
\hline & & & 1.0 & 675.7 & 1.919 & 1351.3 & 2.412 & 2027.0 & 3.260 & 2702.6 & 3.850 & 3040.5 & 4.126 \\
\hline & & & 1.5 & 653.7 & 1.948 & 1307.4 & 2.448 & 1961.1 & 2.799 & 2614.7 & 3.875 & 2941.6 & 4.151 \\
\hline & & Feed & DI water & 713.4 & 1.688 & 1426.8 & 2.122 & 2140.1 & 2.906 & 2853.5 & 3.434 & 3210.2 & 3.681 \\
\hline \multirow{8}{*}{ PRO } & \multirow{4}{*}{20} & Draw & 1.5 & 433.6 & 1.419 & 867.1 & 1.783 & 1300.6 & 2.038 & 1734.2 & 2.241 & 1951.0 & 2.330 \\
\hline & & \multirow{3}{*}{ Feed } & 0.05 & 466.5 & 1.423 & 932.9 & 1.789 & 1399.4 & 2.045 & 1865.9 & 2.248 & 2099.1 & 2.787 \\
\hline & & & 0.5 & 456.7 & 1.388 & 913.4 & 1.745 & 1370.2 & 1.995 & 1826.9 & 2.193 & 2055.2 & 2.705 \\
\hline & & & 1.0 & 446.2 & 1.403 & 892.4 & 1.763 & 1338.6 & 2.016 & 1784.8 & 2.216 & 2007.9 & 2.718 \\
\hline & \multirow{4}{*}{40} & Draw & 1.5 & 653.7 & 1.948 & 1307.4 & 2.448 & 1961.1 & 2.799 & 2614.7 & 3.875 & 2941.6 & 4.151 \\
\hline & & \multirow{3}{*}{ Feed } & 0.05 & 711.9 & 1.897 & 1423.8 & 2.385 & 2135.7 & 3.264 & 2847.6 & 3.857 & 3203.5 & 4.135 \\
\hline & & & 0.5 & 696.5 & 1.902 & 1393.1 & 2.391 & 2089.6 & 3.255 & 2786.2 & 3.846 & 3134.4 & 4.122 \\
\hline & & & 1.0 & 675.7 & 1.919 & 1351.3 & 2.412 & 2027.0 & 3.260 & 2702.6 & 3.850 & 3040.5 & 4.126 \\
\hline
\end{tabular}


Table 4 - Reflection coefficient of membranes in FO and PRO tests.

\begin{tabular}{|c|c|c|c|c|c|c|c|}
\hline \multirow[b]{2}{*}{ Membrane } & \multirow[b]{2}{*}{$\begin{array}{c}\text { Crossflow } \\
\text { Velocity } \\
\text { (cm/s) }\end{array}$} & \multicolumn{3}{|c|}{ FO - DI water feed } & \multicolumn{3}{|c|}{ PRO - 1.5M NaCl draw } \\
\hline & & $\begin{array}{c}0.5 \mathrm{M} \mathrm{NaCl} \\
\text { draw }\end{array}$ & $\begin{array}{c}1 \mathrm{M} \mathrm{NaCl} \\
\text { draw }\end{array}$ & $\begin{array}{c}\text { 1.5M NaCl } \\
\text { draw }\end{array}$ & $\begin{array}{c}0.05 \mathrm{M} \mathrm{NaCl} \\
\text { feed }\end{array}$ & $\begin{array}{l}0.5 \mathrm{M} \mathrm{NaCl} \\
\text { feed }\end{array}$ & $\begin{array}{c}1 \mathrm{M} \mathrm{NaCl} \\
\text { feed }\end{array}$ \\
\hline \multirow{5}{*}{ HTI } & 10.34 & $0.919 \pm 0.037$ & $0.932 \pm 0.021$ & $0.936 \pm 0.019$ & $0.678 \pm 0.018$ & $0.888 \pm 0.023$ & $0.913 \pm 0.027$ \\
\hline & 20.68 & $0.936 \pm 0.026$ & $0.945 \pm 0.015$ & $0.947 \pm 0.017$ & $0.800 \pm 0.017$ & $0.922 \pm 0.020$ & $0.939 \pm 0.029$ \\
\hline & 31.01 & $0.947 \pm 0.021$ & $0.950 \pm 0.018$ & $0.954 \pm 0.016$ & $0.824 \pm 0.019$ & $0.933 \pm 0.018$ & $0.953 \pm 0.017$ \\
\hline & 41.35 & $0.951 \pm 0.023$ & $0.956 \pm 0.016$ & $0.958 \pm 0.015$ & $0.823 \pm 0.024$ & $0.943 \pm 0.014$ & $0.963 \pm 0.012$ \\
\hline & 46.52 & $0.955 \pm 0.022$ & $0.959 \pm 0.015$ & $0.961 \pm 0.014$ & $0.836 \pm 0.011$ & $0.950 \pm 0.015$ & $0.966 \pm 0.012$ \\
\hline \multirow{5}{*}{ Oasys } & 10.34 & $0.890 \pm 0.018$ & $0.899 \pm 0.006$ & $0.910 \pm 0.005$ & $0.736 \pm 0.019$ & $0.869 \pm 0.005$ & $0.885 \pm 0.023$ \\
\hline & 20.68 & $0.921 \pm 0.001$ & $0.928 \pm 0.003$ & $0.932 \pm 0.003$ & $0.828 \pm 0.027$ & $0.918 \pm 0.007$ & $0.920 \pm 0.015$ \\
\hline & 31.01 & $0.935 \pm 0.003$ & $0.939 \pm 0.001$ & $0.942 \pm 0.001$ & $0.868 \pm 0.060$ & $0.926 \pm 0.019$ & $0.933 \pm 0.018$ \\
\hline & 41.35 & $0.941 \pm 0.007$ & $0.944 \pm 0.003$ & $0.948 \pm 0.002$ & $0.868 \pm 0.031$ & $0.932 \pm 0.014$ & $0.941 \pm 0.019$ \\
\hline & 46.52 & $0.945 \pm 0.005$ & $0.947 \pm 0.002$ & $0.952 \pm 0.001$ & $0.876 \pm 0.020$ & $0.936 \pm 0.012$ & $0.946 \pm 0.016$ \\
\hline
\end{tabular}



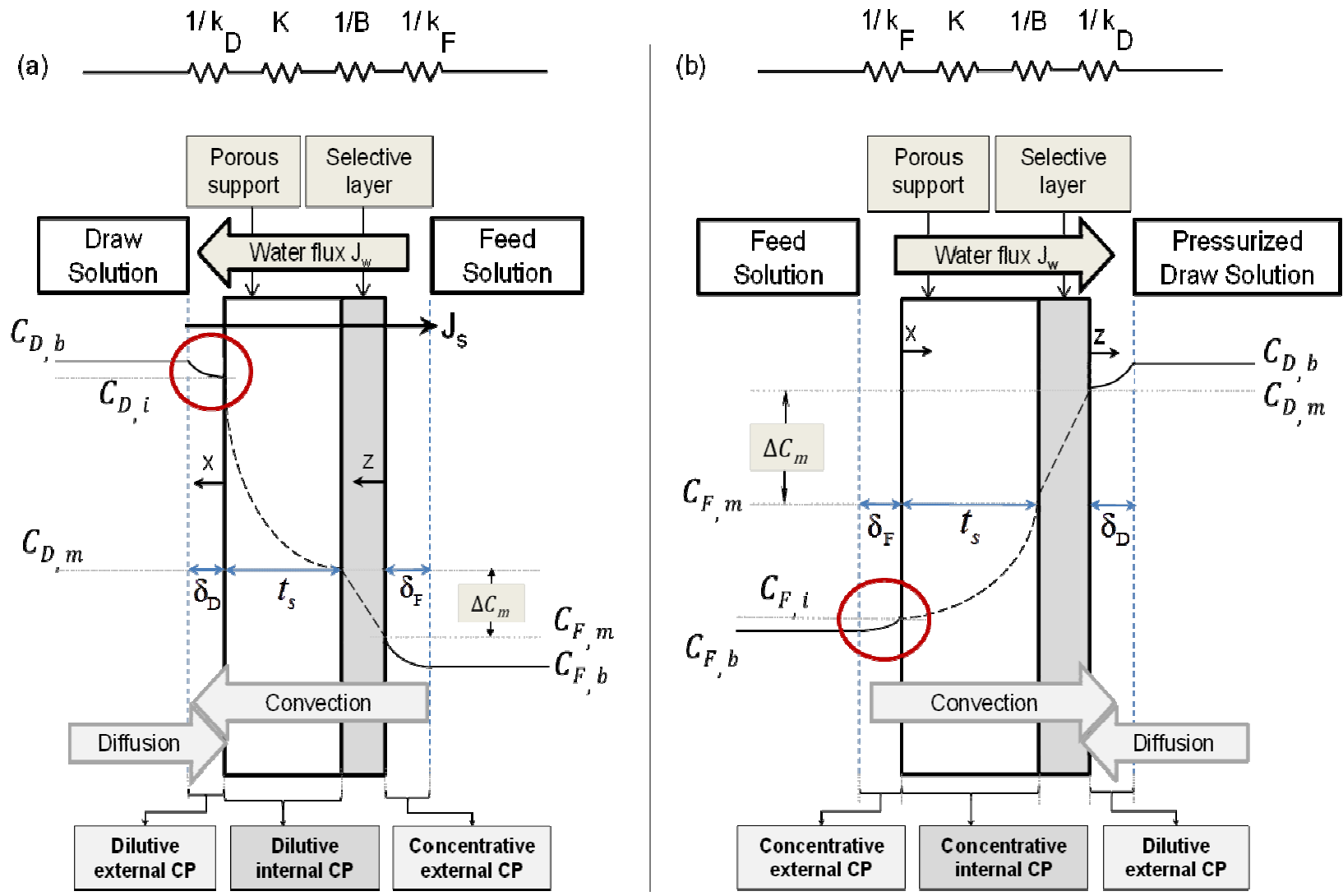

Figure 1 - Schematics of solute concentration profile at steady state across a thin-film composite membrane in (a) FO mode and (b) PRO mode. 


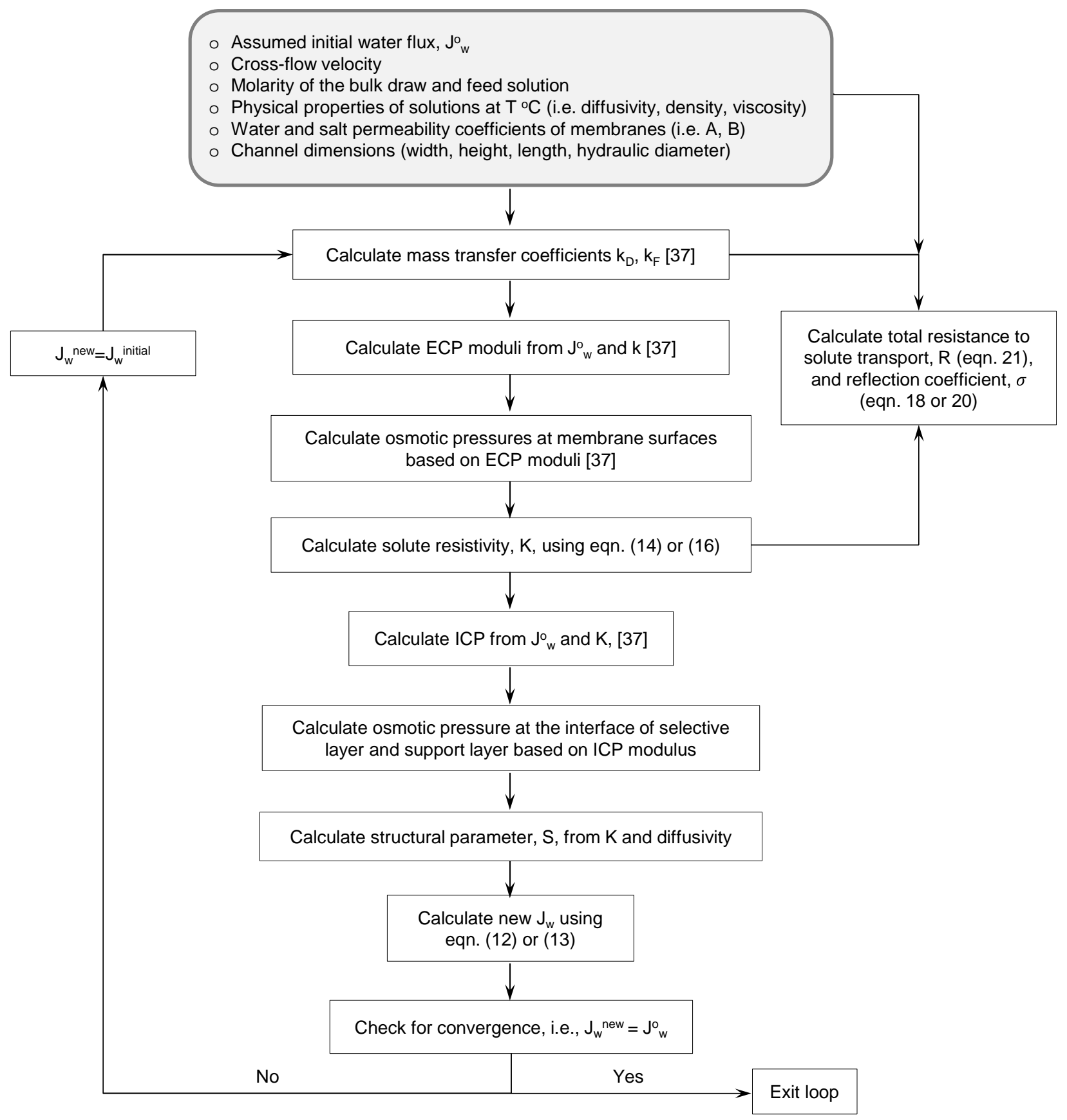

Figure 2 - Iteration procedure using Matlab algorithm to de-convolute ECP, ICP moduli, structural parameter, and mass transfer resistance, given operating conditions (i.e. solutions concentration, temperature, cross-flow velocities, channel dimensions and membranes permselectivity obtained from reverse osmosis tests). 
(a) $\quad \mathrm{HTI}-\mathrm{FO}-20^{\circ} \mathrm{C}-\mathrm{DI}$ Water Feed

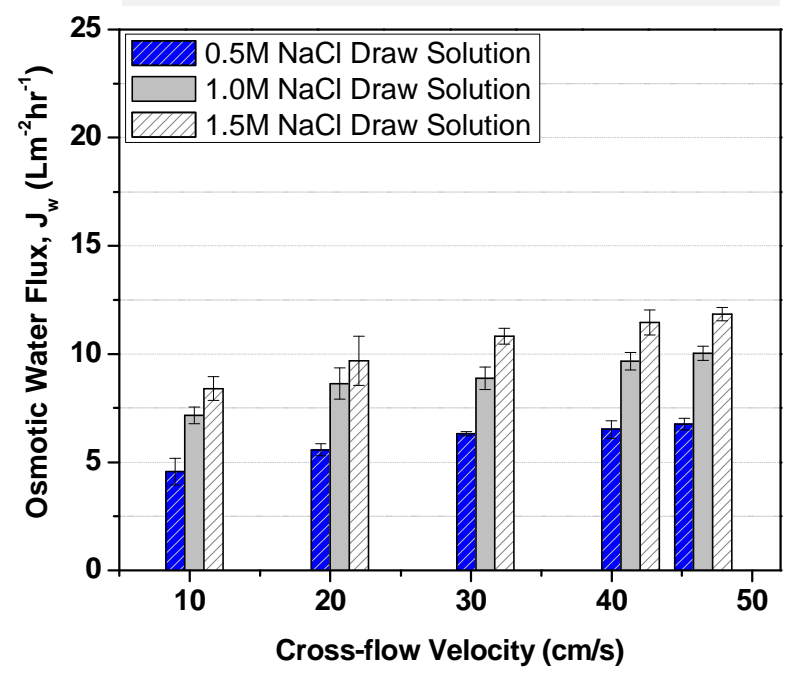

(b) Oasys - FO - $20^{\circ} \mathrm{C}-\mathrm{DI}$ Water Feed

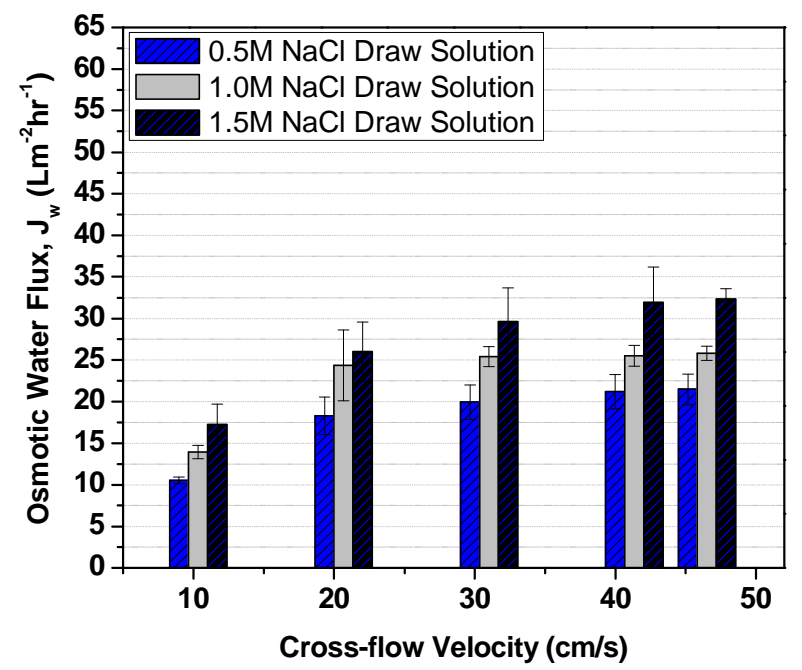

$\mathrm{HTI}-\mathrm{PRO}-20^{\circ} \mathrm{C}-1.5 \mathrm{M} \mathrm{NaCl}$ Draw

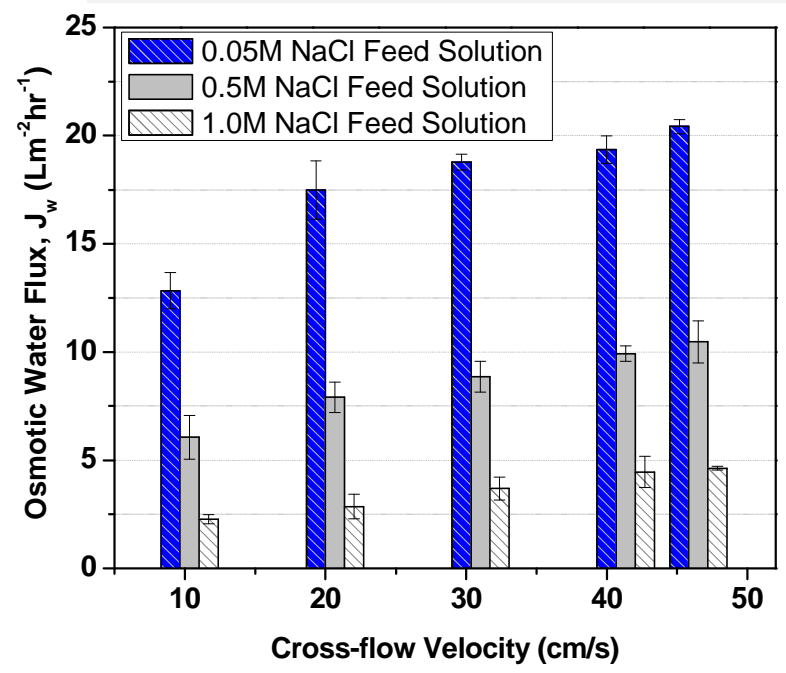

Oasys - PRO $-20^{\circ} \mathrm{C}-1.5 \mathrm{M} \mathrm{NaCl}$ Draw

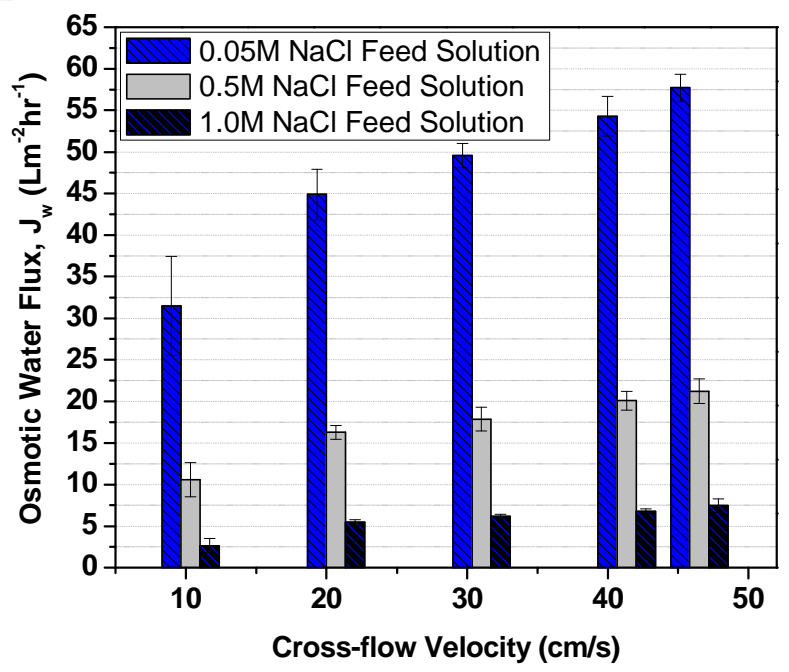

Figure 3 - Osmotic water flux performance of $\mathrm{HTI}$ and Oasys membranes as a function of cross-flow velocity (in FO and PRO modes) at $20{ }^{\circ} \mathrm{C}$. Similar flux behavior was observed at 40 ${ }^{\circ} \mathrm{C}$ (supplementary information). 


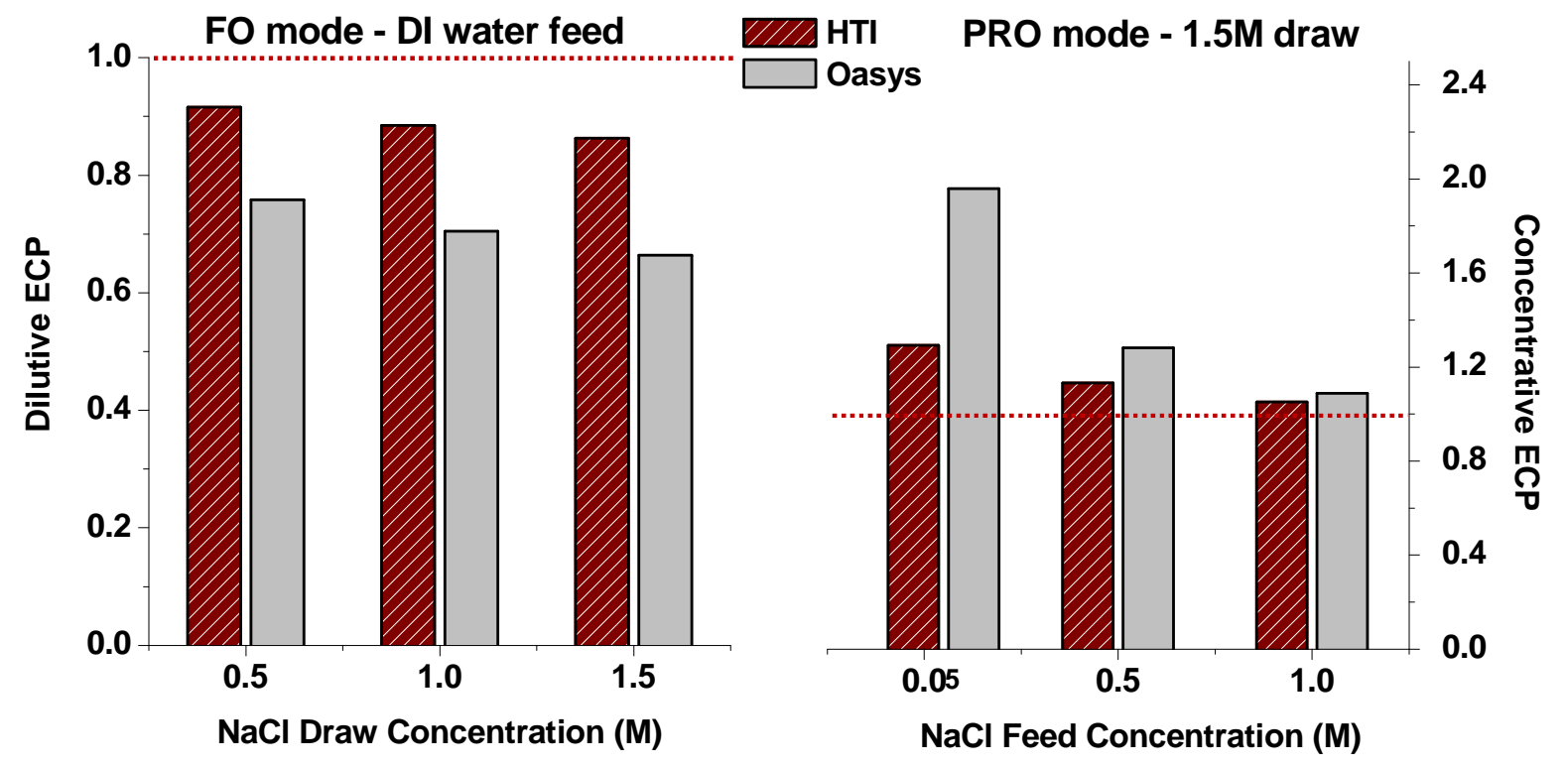

Figure 4 - ECP moduli on the porous side of the membranes in FO and PRO modes obtained from this study. The dash lines represent for the ideal case with no concentration polarization. Data was obtained at $20^{\circ} \mathrm{C}$ and a cross-flow velocity of $\sim 31.0 \mathrm{~cm} / \mathrm{s}$. 
(a)

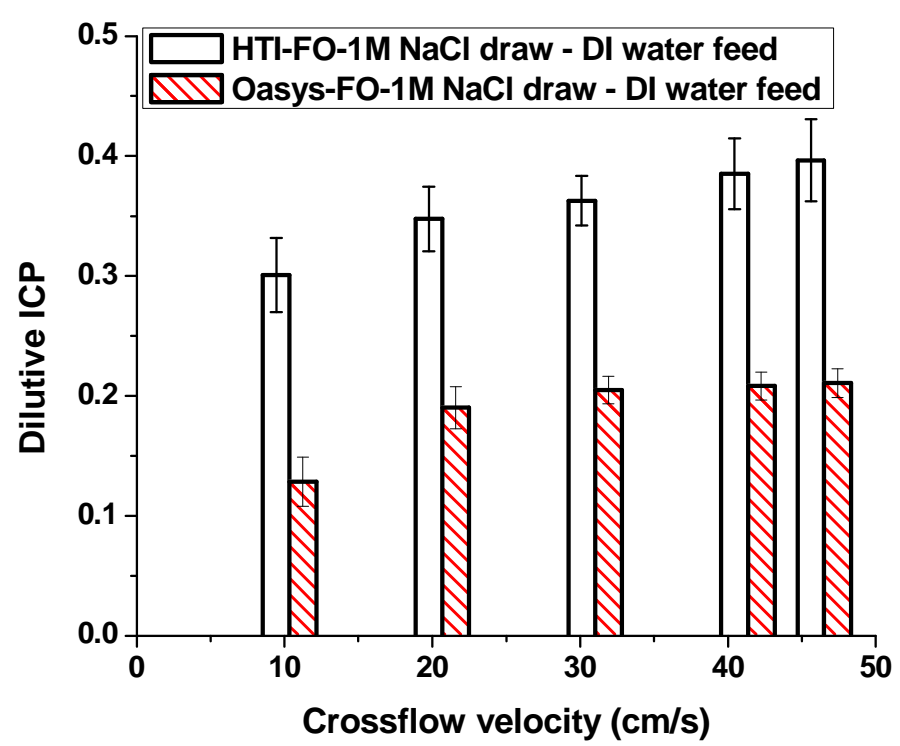

(b)

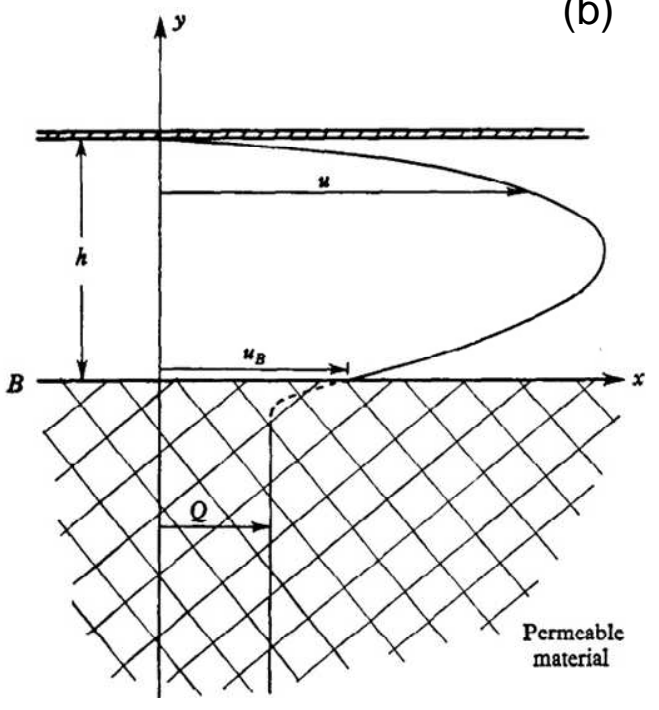

Figure 5 - (a) Change of ICP with cross-flow velocities representatively in FO process and (b) Velocity profile for the rectilinear flow in a horizontal channel formed by a permeable lower wall $(y=0)$ and an impermeable upper wall $(y=h)$ [53] (Reprinted by permission of Cambridge University Press). 

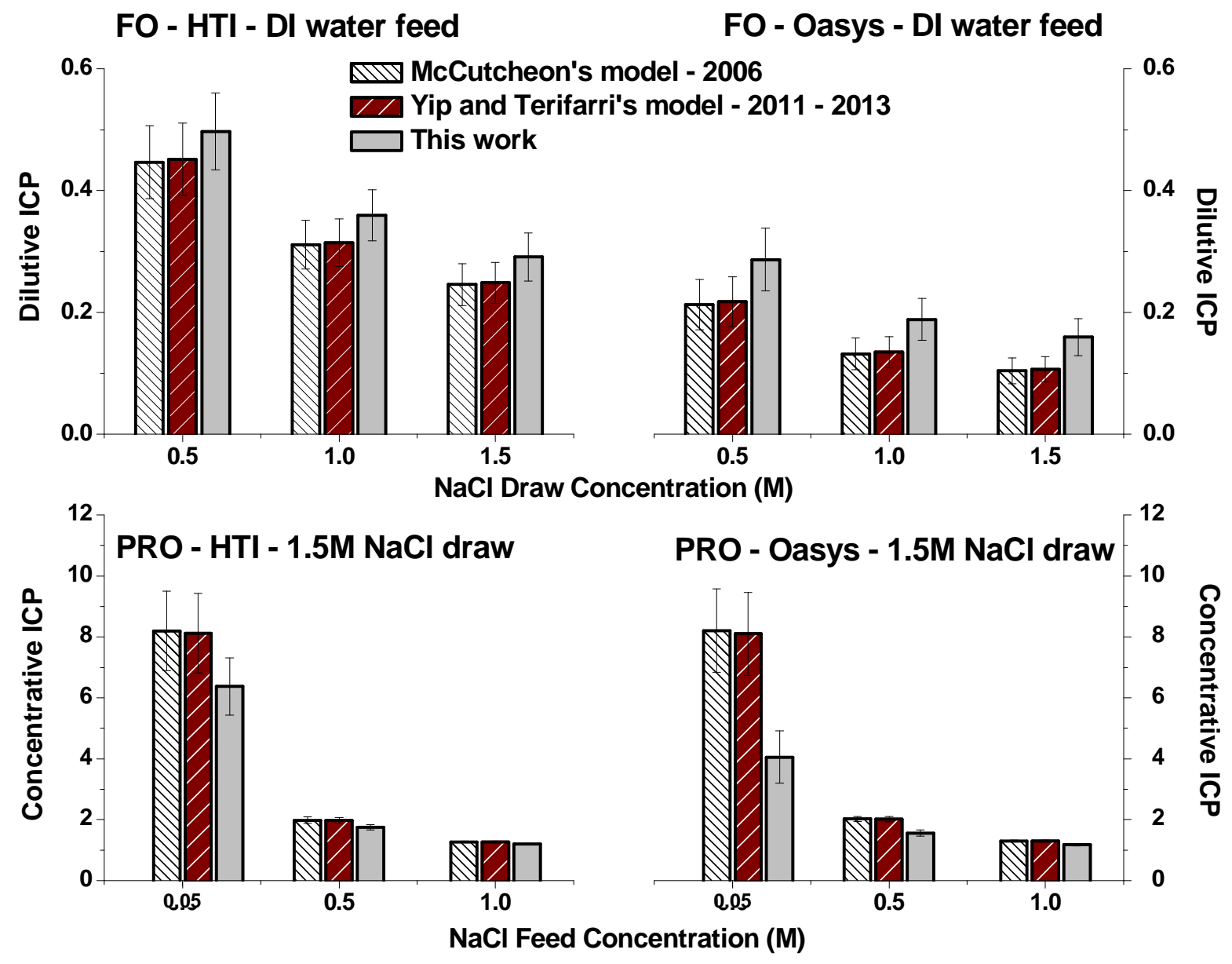

Figure 6 - Comparing ICP modulus from FO and PRO experiments on HTI asymmetric and Oasys TFC membranes using new model and previous models by McCutcheon [38], Yip [21] and Tiraferri [52]. Data was obtained at $20^{\circ} \mathrm{C}$ and a cross-flow velocity of $\sim 31.0 \mathrm{~cm} / \mathrm{s}$. 

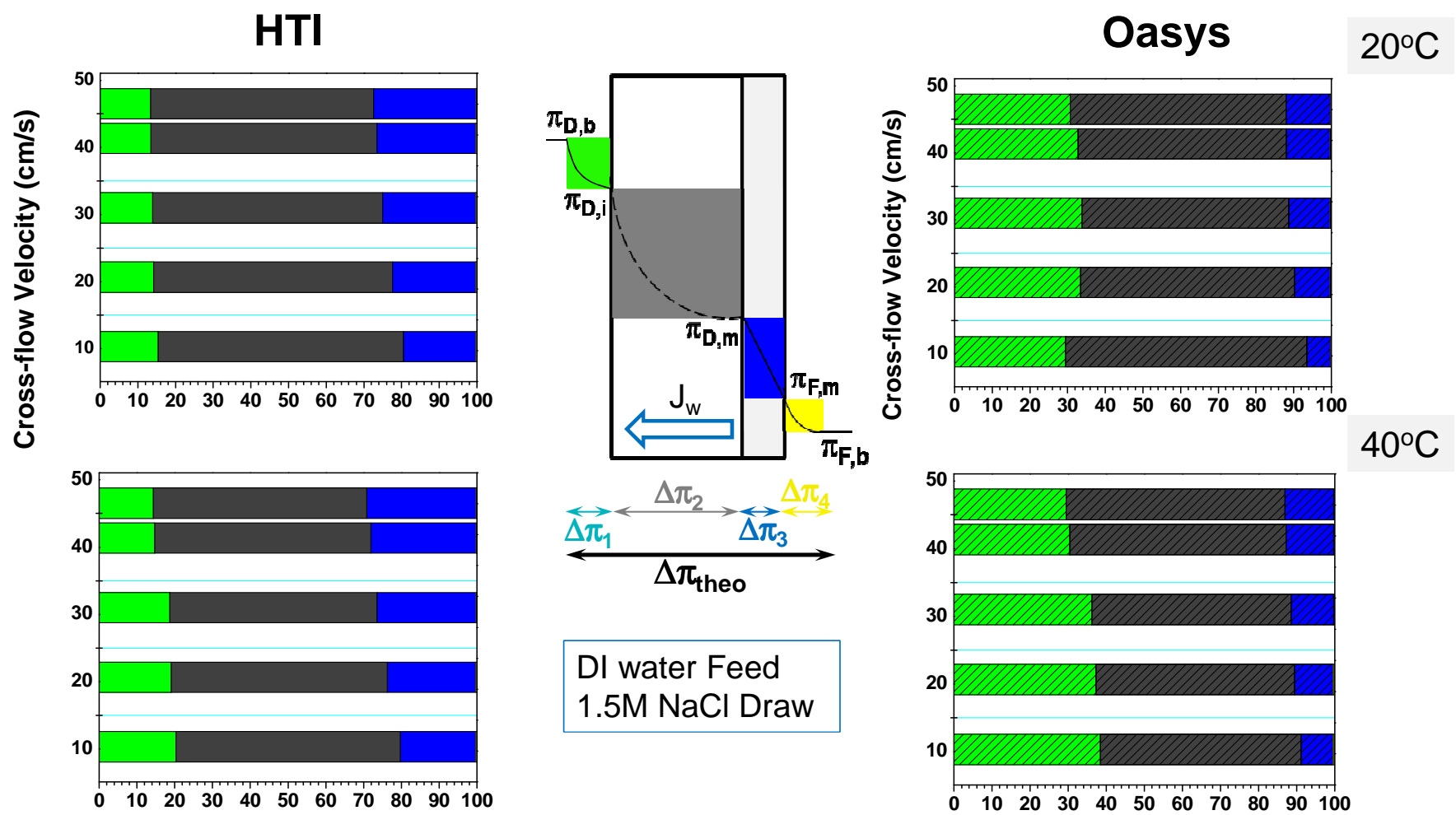

Figure 7 - Lost driving force caused by concentration polarizations in FO mode at 20 and $40{ }^{\circ} \mathrm{C}$. Zero transmembrane pressure difference. Bars represent for percentages of $\frac{\Delta \pi_{i}}{\Delta \pi_{\text {theo }}}$. Blue bars represent for the effective driving force across the selective layer. Note that the contribution of the ECP on the selective layer (feed) side (yellow), although non-zero, was insignificant to be visible in the plots (ranging from $0.2-0.65 \%$, see Appendix 3 ). Please refer to online version to view this image in color. 

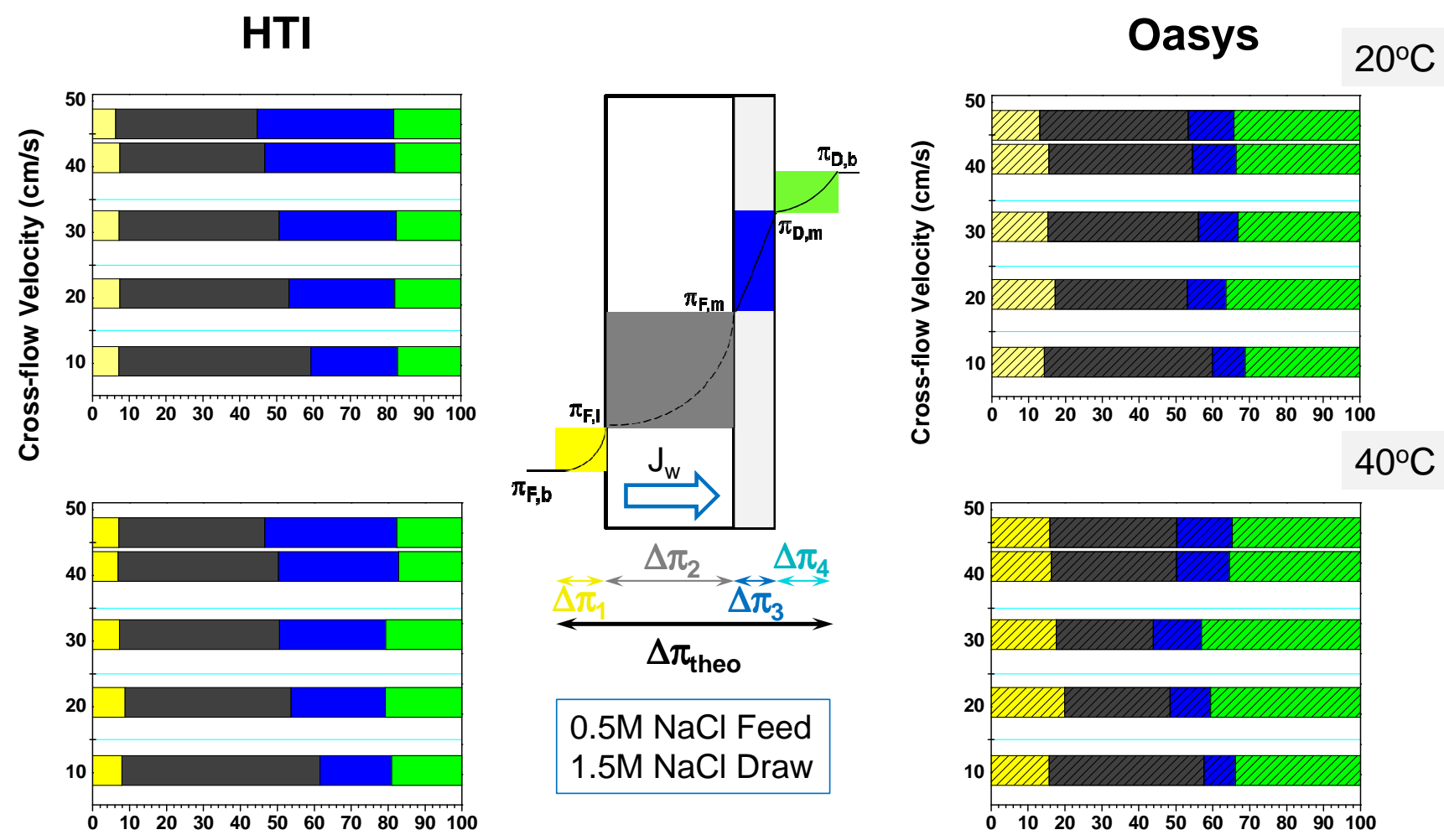

Figure 8 - Lost driving force caused by concentration polarizations in PRO mode at 20 and 40 ${ }^{\circ} \mathrm{C}$. Zero transmembrane pressure difference. Bars represent for percentages of $\frac{\Delta \pi_{\mathrm{i}}}{\Delta \pi_{\text {theo }}}(\mathrm{i}=$ $1-4)$. Blue bars represent for the effective driving force across the selective layer. Please refer to online version to view this image in color. 


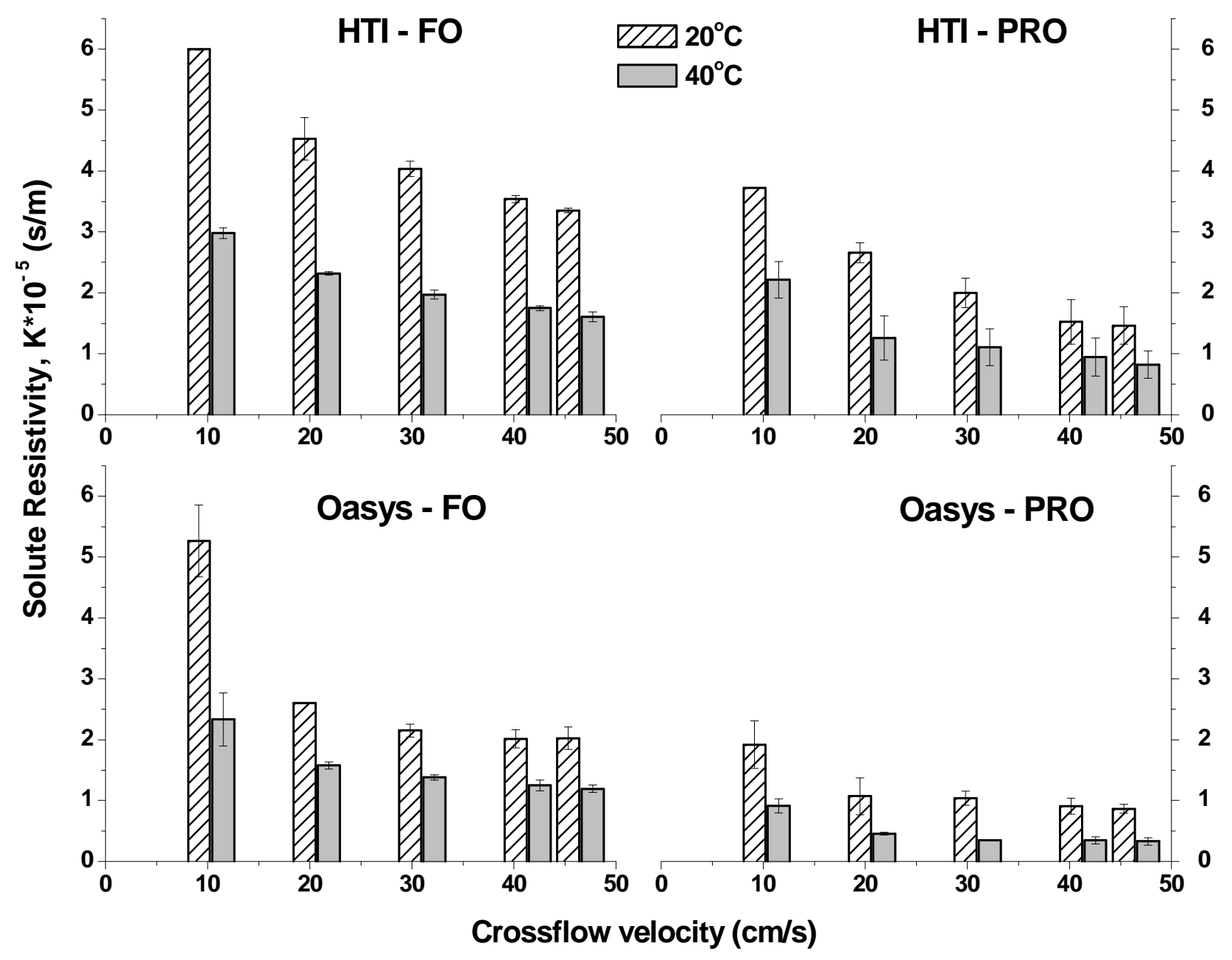

Figure 9 - Solute resistivity, $\mathrm{K}$, of $\mathrm{HTI}$ asymmetric and Oasys TFC membranes at different crossflow velocities and temperatures. Data was averaged from independent tests of different membrane coupons across the ranges of solution concentration. 


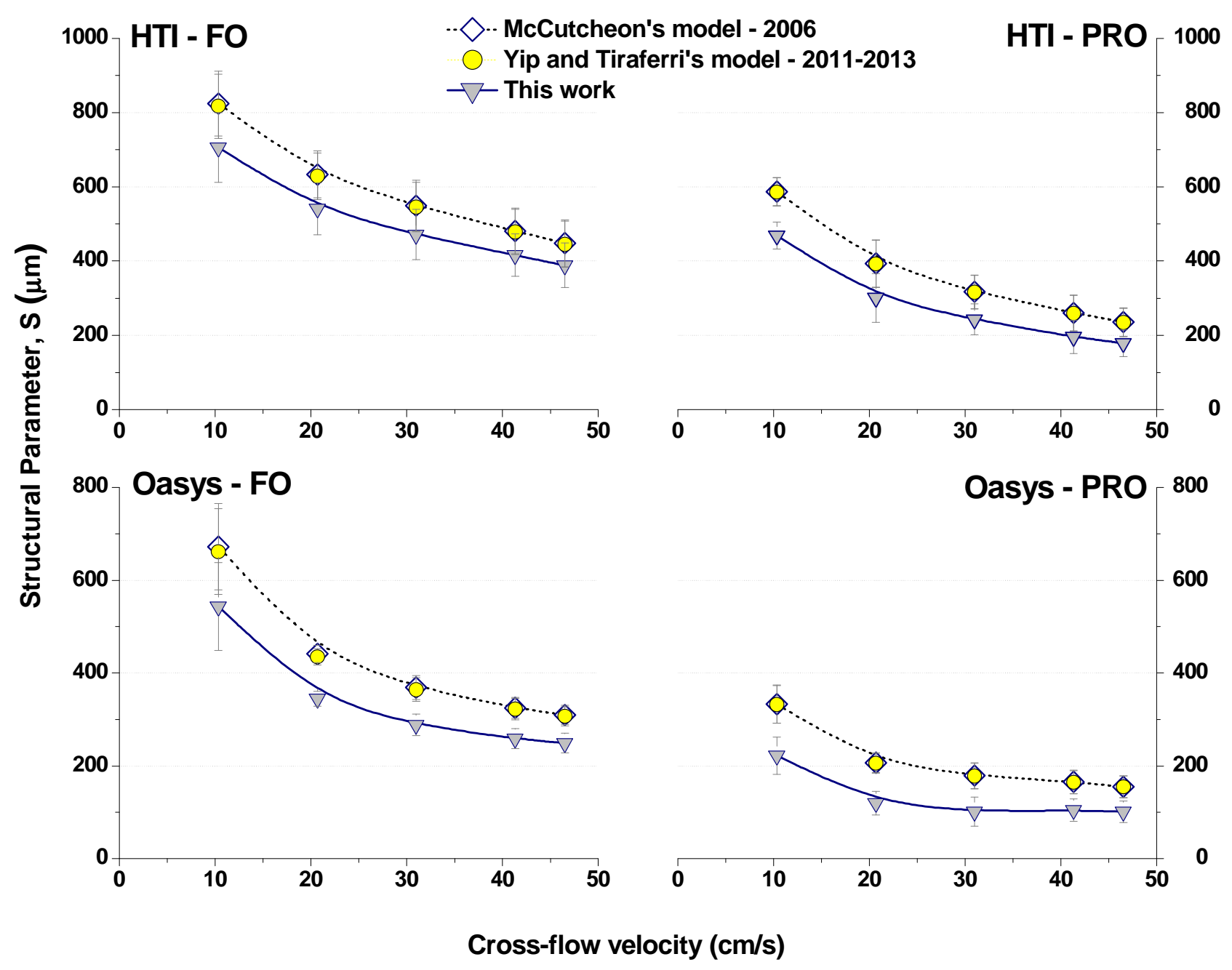

Figure 10 - Structural parameter of HTI and Oasys TFC membranes vs. cross-flow velocity in FO and PRO tests obtained from different models. Data was averaged from independent tests of different membrane coupons. 


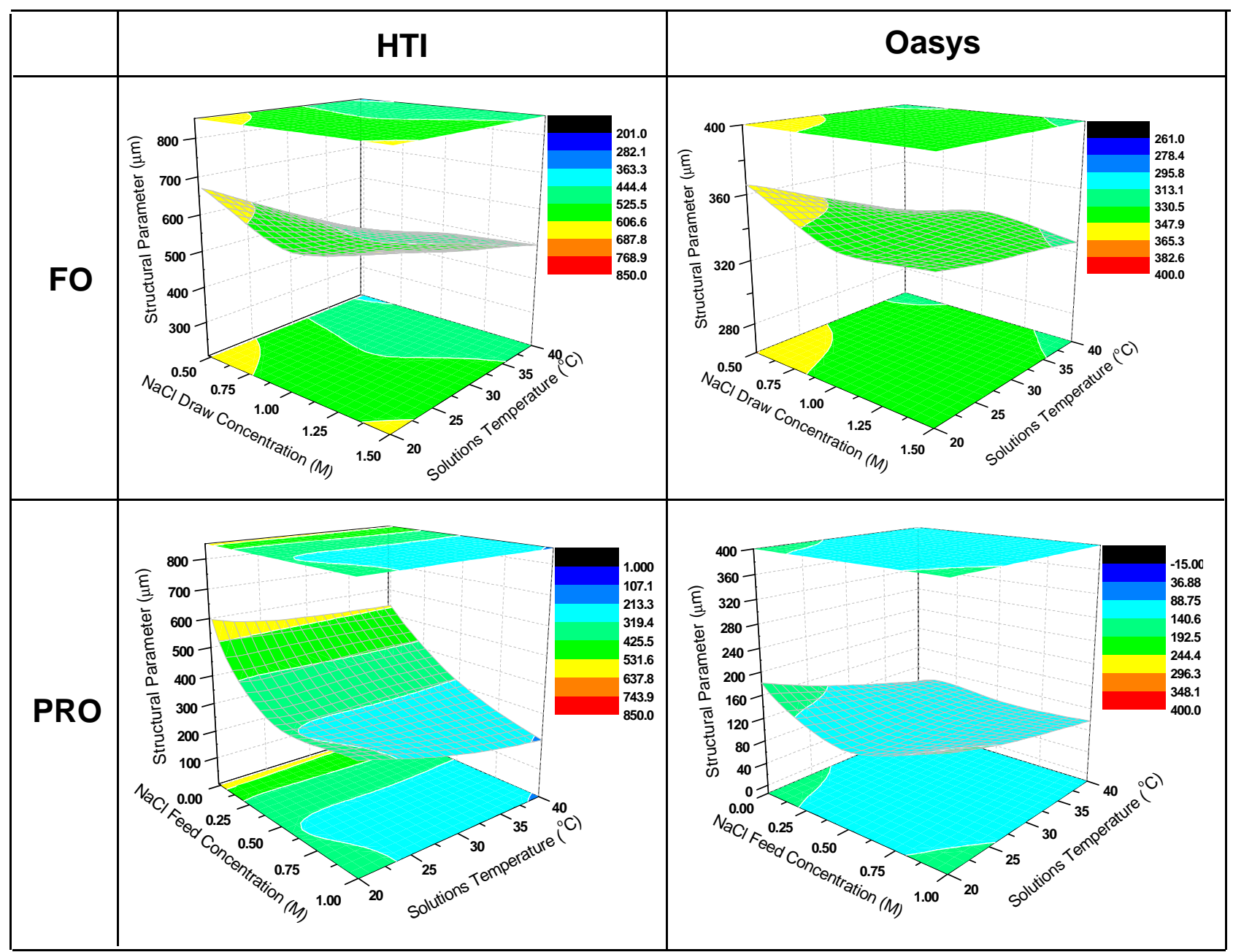

Figure 11 - Impacts of draw and feed solutions temperature and concentrations on the structural parameter of $\mathrm{HTI}$ and Oasys TFC membranes in both FO and PRO modes. 


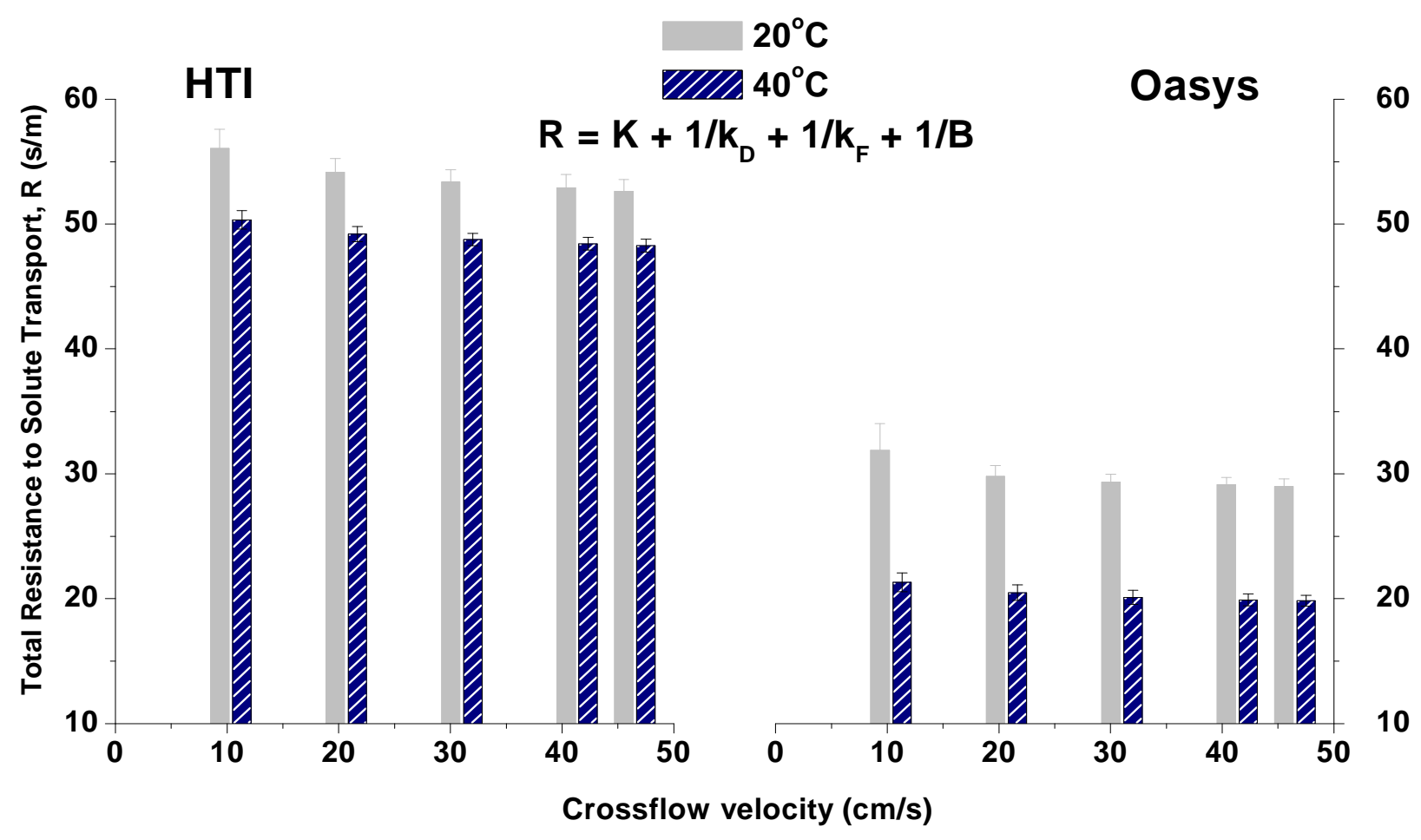

Figure 12 - Changes of total resistance of membranes to solute transport with cross-flow velocity and testing temperature. Eqn. (21) was used to obtain total resistance to solute transport. Values were averaged from independent data of different membrane coupons across the ranges of solution concentration in both $\mathrm{FO}$ and $\mathrm{PRO}$ modes. 